\title{
How Does Sustainability Affect Consumer Choices in the Fashion Industry?
}

\author{
Leandro Pereira ${ }^{1,2, *(\mathbb{D})}$, Rita Carvalho ${ }^{1}$, Álvaro Dias ${ }^{1,3}$, Renato Costa ${ }^{1}$ (D) and Nelson António ${ }^{1}$ \\ 1 Business Research Unit, ISCTE Business School, 1649-026 Lisbon, Portugal; arcco3@iscte-iul.pt (R.C.); \\ alvaro.dias@iscte-iul.pt (Á.D.); renato_jorge_costa@iscte-iul.pt (R.C.); nelson.antonio@iscte-iul.pt (N.A.) \\ 2 Winning Lab, 1750-149 Lisbon, Portugal \\ 3 School of Economic and Organizational Sciences, Universidade Lusófona de Humanidades e \\ Tecnologias/TRIE, 1749-024 Lisbon, Portugal \\ * Correspondence: leandro.pereira@iscte-iul.pt
}

check for updates

Citation: Pereira, L.; Carvalho, R.; Dias, Á.; Costa, R.; António, N. How Does Sustainability Affect Consumer Choices in the Fashion Industry? Resources 2021, 10, 38. https://doi.org/10.3390/resources 10040038

Academic Editor: Elena Cristina Rada

Received: 9 March 2021

Accepted: 13 April 2021

Published: 19 April 2021

Publisher's Note: MDPI stays neutral with regard to jurisdictional claims in published maps and institutional affiliations.

\begin{abstract}
The fashion industry being one of the most polluting industries in the world means that it is an industry with an immense potential for change. Consumers are central and are closely intertwined with how companies act. This research reflects consumer perspectives and practices towards the topic of sustainability implemented in the fashion industry. The relevance of sustainability in the fashion industry and the key role of consumers in its implementation are undeniable and confirmed by consumers in a representation of general awareness and concern, despite not always being translated into actual practices. A qualitative research methodology, followed by a set of interviews conducted with consumers, revealed that the great majority are implementing a variety of practices when making their buying choices towards fashion items. Barriers such as lack of education, information, knowledge and transparency were identified, and this aspect was shared by consumers as a reason why they are not motivated to make more conscious decisions. Companies should educate consumers from a general perspective and focus on the group of consumers that are not implementing sustainability in the fashion industry in their buying choices, as they represent the potential for the future.
\end{abstract}

Keywords: sustainability; fashion industry; consumer behavior

\section{Introduction}

The concept of sustainability is gaining increased global attention and is nowadays a very important topic under analysis in industries all over the world. It is particularly pertinent to speak about sustainability when implemented in the fashion industry as it is one of the most polluting industries in the world, with a huge environmental, social and economic impact $[1,2]$.

In the fashion industry, there is an excessive consumption of natural resources and an enormous use of chemicals used during fiber production and dyeing that are harming the environment and societies day after day [3]. The greenhouse gas emissions in the apparel industry account for a significant part of the global carbon emissions, due to the energy used during production, manufacturing and transportation from the millions of garments that are purchased globally each year, which together form a complex supply chain. Frequently, production locations are moving site in the search for cheaper labor costs, and this practice is generally linked with issues related to limited or non-existent worker's rights [4].

Furthermore, due to the strong implementation of fast fashion as a main trend and the increasingly fast paced cycles, consumer habits in general have changed towards a massive amount of garments acquisition that has resulted in tons of waste and pieces ending up in landfills [5]. 
In the past years, there has been the urge to reverse these practices towards sustainability implementation, with firms implementing a variety of initiatives such as circular economy, fair trade, lowsumerism and sharing economy as well as changing their perception towards a new way of value creation that has sustainability as a focal aspect [6]. For McNeill and Moore [5], this is achievable in the long term if consumers support sustainable fashion by purchasing it.

Recently, the perception of sustainability has increasingly taken an outstanding role, principally because of its potential ability to influence consumers' views and consequently their buying choices [7]. Consumers play a big role in sustainability implementation and are an integral part of it. They are the engine that motivates companies to act in a certain way. Frequently, consumers set the pace for many businesses and guide them towards the practices they should implement. This is in line with Brozovic et al. [8], who explain the multi-actor perspective as a driver for sustainability implementation.

McNeill and Moore [5] state that, although consumers are said to increasingly care about unethical behavior, this attitude does not always translate to a change in behavior and this is generally caused by a lack of knowledge about the negative effects of the fashion industry. However, Biswas [9] concludes that trends are changing, and an increasing number of customers are exhibiting a positive impulse towards green product purchase in general. The authors have a distinct point of view; however, this can be explained by the evolution of human culture knowledge and ethics over time. Based on the literature, one can realize that consumer choices are in general changing towards sustainability implementation; nevertheless, a concrete notion of actual facts is a clear gap that this research intents to cover. The aim of this research is to cover the gap of concrete information about how sustainability is affecting the way consumers are acting nowadays, basically how consumers are adapting their buying choices facing the implementation of sustainability in the fashion context, and how their behavior has changed in the past years. The results of this research will be relevant for a deeper comprehension of the actual consumer behavior towards sustainability in the fashion industry and this will further help firms to implement or adjust practices with a wider and more accurate notion of the real facts. Understanding how consumers are acting nowadays will enable a realistic point of view that will support the development of sustainability in the fashion concept.

The structure of this research is divided into four main chapters: (1) Literature review; (2) Methodology; (3) Data analysis; (4) Discussion and findings. The literature review enables a general view of the three main topics relevant for further developments-sustainability, fashion industry and consumer behavior. For the methodology, a qualitative analysis is done in the form of interviews, with a heterogeneous sample, encompassing people from both genders and a wide spectrum of ages, social classes and educational abilities. All this data will further be considered in the data analysis and discussed in the chapter of Discussion and findings.

\section{Literature Review}

In order to further be able to deeper understand the area under study, the literature review is divided into three main topics of relevance-sustainability, fashion industry and consumer behavior. A general knowledge of these topics is essential for further research as well as to come to the final results. This section enables the creation of a general context for research, where doubts and gaps are identified, and a critical analysis is made that enables the intersection of some authors' ideas.

\subsection{Sustainability in the Fashion Industry}

The term sustainability originates in the French verb soutenir, "to hold up or support" [10]. Later, it was relocated to the context of ecology, as a principle of respecting the ability of nature to regenerate itself [11]. Sustainability emerged into a more common topic in the 1980s [12]. The Brundtland Commission presented the most commonly accepted definition of sustainability in the Bruntland Report, our common future, as "development 
that meets the needs of the present without compromising the ability of future generations to meet their own needs" and is credited with popularizing the concept of "sustainable development" $[12,13]$. Despite being initially driven by environmental concerns, the term sustainable development and sustainability has, since then, taken in a variety of expectations for desirable progress: "the concrete challenges of sustainable development are at least as heterogeneous and complex as the diversity of human societies and natural ecosystems around the world" [11]. In 2002, after the world summit, the triple bottom line concept-also known as the three pillars of sustainability, encompassing people, profit and planet-came out as being the balanced integration of economic, environmental (or ecological) and social performance [11].

This tripartite description is generally presented in the form of three intersecting circles representing society, environment and economy, with sustainability being placed at the intersection, as shown in Figure 1 below and regularly affecting each other. This graphic is found in diverse forms as a description of 'sustainability' within the academic literature [12] and is a clear visual representation of the broadness and variety in the representation of the concept under analysis. Furthermore, it helps with gaining a clear overview of the fundamental aspects of Sustainability.

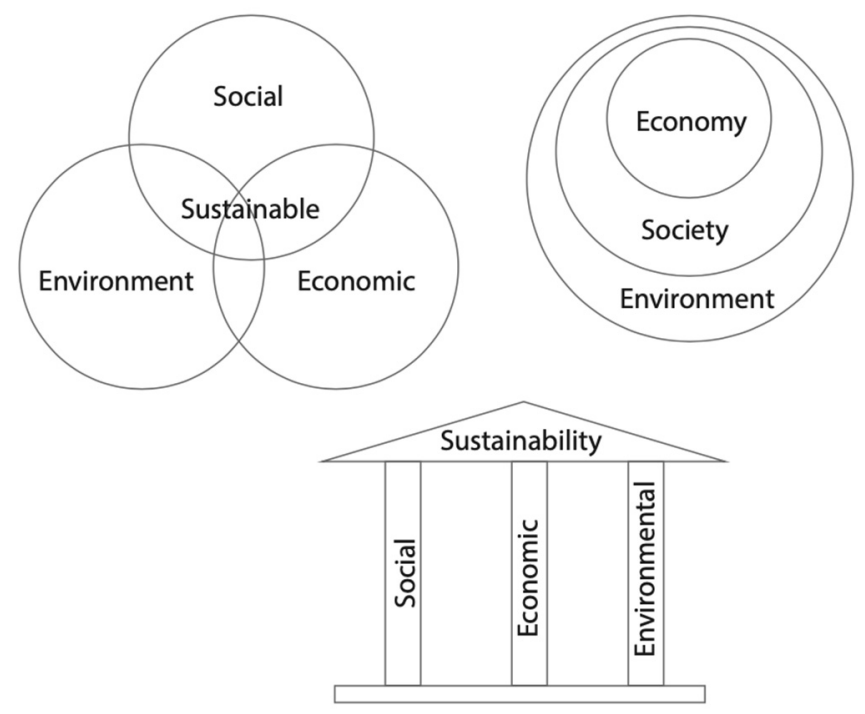

Figure 1. Three ways of sustainability representation.

Originally, all three dimensions were treated as equal and balanced, although interventions should be prioritized according to the different contextual differences [11]. In order to turn the triple bottom line ("TBL") into a more operational approach, many studies and experiments have been made, with the creation of standards, codes and metrics. Although the notion of sustainability was most effectively translated to the corporate context by the TBL framework, it is now seen as the business paradigm for the 21st century. In 2015, during the Paris agreement, the Sustainable Development Goals ("SDG's") and the sustainable agenda for 2030 were adopted between the United Nations and 195 countries. These reflect the global consensus, that a change is needed and a different trajectory for sustainability must be implemented [14]. The temporal dimension for sustainability is open-ended, it is still a concept under progress and, thus, goals can be constantly adapted or reframed over time [12]. Many definitions of the terms Sustainable Development ("SD") and sustainability have appeared over the past decades and these have been considered to be complex, controversial and challenging, as they are open to different interpretations. The fact that the theme is being intensively debated and is therefore under continuous discussion and research [15], reflects the multi-dimensional character of the sustainability concept, which includes not only ecological, political and ethical but also socio-economic, democratic, cultural and technological development [13]. Due to the fact that there is no fixed definition 
that matches all the areas of sustainability implementation and practices, some authors estimated that there are around 300 possible definitions that describe sustainability in different industries or contexts [11]. As a result of such openness, models of sustainability are not able to present a fixed aim. Sustainability is rather a system of objectives with components. It embodies a pluralistic model, which can be represented in concrete terms through varied processes in many areas [13]. Broadly, the principle means not using more resources than can be regenerated during the same period. The core of sustainability, however, encompasses the planning and anticipation of the economy in the ecological cycle and its rhythms of time. Therefore, it is necessary to reflect on the conditions and consequences of human activities for current and future generations. Sustainability must be understood as a process of actively and innovatively searching, learning and shaping the present and future of human activities on Earth [13]. The open concept of sustainability requires the participation of public life by civil society. Consciousness and responsibility can thrive, through recognition and participatory shaping. So, cooperation is an essential element of the ethical principle of sustainability. Sustainability requires innovations and a multi-dimensional approach is needed, that would open up spaces in society for a change in values. It means more than anything else, a new ethical-cultural orientation [13].

In addition, it implies applying new limits and goals for progress further than "faster, higher, farther". Vogt and Weber [13] even conclude that preserving the ecological, social and economic stability of human living spaces will be a central principle and that sustainability therefore also requires a systemic and anchored ability for people to become self-sufficient (thrifty) and efficient (technologically optimized). Moreover, sustainability requires the substitution of resources. Being able to link innovative technology with organizational optimization with changes in personal attitudes is an essential point. The protection of nature should be a cultural task and integrate the quality of the environment as a fundamental value in definitions of wealth, at the cultural, social, health-related, political and economic levels. Sustainable culture expresses a rediscovery of the ethics of moderate living. A sustainable lifestyle is not only based on wealth but rather aims to achieve intelligent, resource-friendly and environment-friendly patterns of consumption [13].

Furthermore, Vogt and Weber [13] even argue that the responsibility for nature during climate change, the rising number of human beings on Earth, and the scarcity of resources are not a problem of knowledge. The main problem is of conviction and belief-we know about climate change and environmental issues but in the other hand we do not understand, in a deeper sense, what the scientific data are telling. They even state that people cannot adequately imagine what the data mean for us and for people all over the world or in general for life on Earth. Thus, we are unable to react adequately because we have never experienced such a deep and complex change of living conditions. Ramos et al. [15] conclude that the main drivers for environmental practices vary in each culture and depending on each context. This conclusion is very pertinent in general, but also specifically if we analyze developing and developed countries. Many stakeholders, and society in general, have been increasingly putting pressure on companies to implement ecological and social sustainability. Simultaneously, sustainability reporting has become popular, as well as the Global Reporting Initiative ("GRI"), the most implemented global guideline for corporate sustainability reports [16]. The sharing of ways of doing and perspectives on sustainability may be achieved if the different actors are aligned with specific goals [8]. Brozović et al. [8] mentioned that firms are doing their best to engage more actors in sustainability, as this enables an alignment in terms of value, stimulating resource integration. The sharing of standards and principles along with communicating the results of firms' actions through sustainability reports could help improve sustainable practices. However, [17] concludes that some firms avoid providing information about their sustainability performance when their social and environmental results are poor. This suggests pessimistic conclusions about the capability of this reporting process to encourage the integrative management of corporate sustainability. There is a lack of transparency that creates a barrier in the 
implementation of those practices or brands are trying to impress consumers with actions they are not having, and consequently implementing greenwashing.

In addition, firms that are oriented toward sustainable outcomes should consider the value of involving actors in shaping new value creation processes and should refer to them not only as addressees of sustainable outcomes but also as contributors. A multi actor perspective could be a solution for the incorporation of sustainability. Some argue that external pressure from stakeholders has a bigger impact on firm behavior and consequently its performance than internal goals and pressure. Stakeholder engagement requires that the stakeholders are convinced that they have a certain influence by engaging in an information exchange on the basis of sustainability reports and that the information in the report is perceived as trustworthy and relevant [18]. The concerns for sustainability are more and more present into both the agendas of policymakers and the strategies of companies. A precise policy requires a wide understanding of current environmental trends and their potential consequences for humans and ecosystems now and in the future [19]. Sustainability in practice requires changes in practices, behaviors and ways of thinking $[20,21]$ from individuals, households, companies, public administration, academia and non-government organizations, as well as the strategic and policy levels of governments [15]. In this context, governments have committed to sustainability transitions (for example by adopting the 2030 Sustainable Development Agenda, United Nations General Assembly, 2015), where the SDGs were developed, while businesses and consumers citizens have been engaged in initiatives and behaviors towards change, for example through Corporate Social Responsibility ("CSR") and Corporate Sustainability ("CS") schemes or by adopting alternative consumption habits [22]. Nevertheless, the scale and urgency of the transitions required are very high and managing such processes is still a major challenge for all $[14,23]$.

Furthermore, improvements in design and technology can improve the extension of product life, reducing the demand for raw materials and energy [24], which is a big step forward in sustainability implantation. The future cannot be calculated, and the needs and competences of future people are not fully known, therefore freedom should be prioritized. Thus, the idea of equal distribution of resources among generations is of little practical help in many areas. The aim should rather be to leave to posterity a world that offers enough free space and enough chances. This would enable future generations to make their own decisions and further develop their capabilities [13]. The world is complex and so is sustainability. Complexity, uncertainties and interactions of physical, biological and social systems disorient companies about their actions and decisions on the path to sustainability. The increasing complexity calls for new approaches to corporate sustainability management and research [25] and has significant implications on how decision-making is framed [16]. Specifying the sustainability concept in the fashion industry, it is one of the most polluting industries in the world [2]. Business models of companies in the global fashion industry produce highly negative outcomes for the environment. Excessive water consumption, pollution from chemical treatments used in dyeing and preparation and the destruction of large amounts of unsold stock through incineration or landfill deposits merge to make clothing one of the highest impact industries on the planet [3]. Current organizational changes in the fashion industry started approximately 30 years ago when the traditional luxury fashion industry's long-established solid structure was confronted by diverse environmental changes, particularly globalization, changes in its customer base and the arrival of competitors into previously protected markets. This stable situation has evolved towards a new model called fast fashion. Fast fashion is characterized by articles that can be bought by the masses. This business model has contributed to an increased volume of products with shorter life cycles, followed by the deflation of retail prices [26], which aims to attract customers into stores as frequently as possible in order to increase the buying frequency [27]. The strong implementation of fast fashion as the preferred business model has led to a throwaway culture in which fashion is acquired, worn, and disposed of quickly. The lead time for the creation of these garments is very short in many cases one month, and items are constantly replaced to keep up with every trend that change 
frenetically [2]. The constant changes in fashion trends quicken new designs and sales of fashion products that drive consumption and in turn contribute to its underutilization and waste. The risk of fast-fashion activities is associated with the behavior of both customers and firms. Customers are supporting a system that encourages disposability, with the subsequent societal and environmental challenges [1]. Companies have the urge to adapt their processes and structures to survive in a market of immediate demands and cheap prices, which can involve dangerous labor practices that violate human rights, production in unsafe environments or even in sweatshops and developing countries [2].

Generally, some workers suffer from labor-related problems such as low wages, overtime without pay, no leave, unsafe working conditions, and lack of sanitary facilities. The other problems are child labor, forced labor, unavailability of safety working aids and even no maternity leave [4]. Due to the fact that in recent decades, the fast fashion industry has been characterized by widespread operations across both developing and developed countries [27], there has been an increase of environmental impacts in those regions [26].

However, fashion industries are under tremendous pressure to comply with sustainability norms [4]. Due to economic, social and environmental problems, companies more and more focus on sustainability and try to ensure the same quality and standards in working and production conditions throughout their supply chains [27].The implementation of all these practices, have highlighted the extent of the fashion industry's sustainability problems, that are defined by the balanced integration of economic performance, social inclusiveness, and environmental resilience to the benefit of current and future generations [28]. Fashion needs to manage the use of substantial amounts of materials and energy in production [29] but also its social sustainability through the selection and monitoring of suppliers [26]. Environmental impacts involve all aspects of the fashion business' upstream and downstream supply chains and their transparency but also the less controllable elements of clothing use and disposal [30]. Fashion companies are extremely sensitive to the new challenge emerging from recent sustainability scandals [31]. The complexity and variety of fashion products, the need to differentiate through design content, among other aspects, present huge business challenges when trying to operationalize concepts of sustainability so that they become value-adding propositions.

Furthermore, there is a huge gap between forecasted and actual consumer demand, which can lead to heavy markdowns and excess inventory that erode retailers' profits. Uncertainty is inherent, owing to seasonal and fashion changes, and factors of size and personal preference [32]. Awareness of the need for more sustainable strategies and practices, has led to the development of a circular model of fashion production and consumption based on the principles of the circular economy. The circular economy is understood as an umbrella concept, a phenomenon that creates a relationship between pre-existing independent concepts that aims to develop a regenerative economic system by intentionally slowing, closing, and narrowing material and energy loops [28]. The aim is to keep resources in active use for as long as possible, extract the highest possible value from them while in use, and recover and recycle them at the end of their life [26,33]. In this way, the circular fashion production and consumption model can extend into the consumer use, collection, recycling and re-use of garments [26].

Furthermore, there are other current macro trends when speaking about current sustainable and innovative business models in fashion businesses like sharing economy, collaborative consumption. That are challenging traditional mass production paradigms. Collaborative consumption is not only a cultural reaction against consumption, but also a conscious and efficient alternative for adapting collective and individual needs to available resources. It refers to the expansion and reinvention of exchanging, swapping, sharing, loaning, and donating practices, generally between people not previously connected.

Also, technological innovations are enabling more sustainable practices and can help brands and retailers better deal with the gnawing problem of demand uncertainty [32]. Other prominent developments are alternative fibers or the use of synthetic raw materials instead of scarce natural resources [6]. With the rapid expansion of the global awareness 
of ethical responsibilities to the economy, society and the environment, the adaptation of sustainable practices is strongly progressing in supply chain networks. The implementation of sustainable practices within the fashion supply chain has been one of the areas receiving increased attention due to global competition and stricter regulations [4]. The fashion industry is also characterized by highly horizontal value chains [31] that require close collaboration between the multiple stakeholders that comprise fashion global networks [34]. The implementation of sustainability in the fashion industry is dependent on the synergy between the multiple actors involved in its development. However, there are still some organizations facing difficulties to integrate stakeholders in their sustainable innovation development processes. Because of the pressure with laws and legislation, pressure in reducing costs, search of competitive advantage, technological leadership and consumer market pressure [34].

Furthermore, the fear of sharing knowledge, lack of communication and coordination channels as well as a huge competitive environment between companies, stakeholders and the market in general are elements that create a big barrier in the industry [26]. Legere and Kang [2] present the slow fashion concept that focuses on more than the materials from which clothes are made. It also emphasizes slowing down both the production and the consumption processes, encouraging sustainable values among all who are part of the fashion system. The authors argue that this is a promising alternative to the current fast fashion model, however consumers have been reluctant to fully embrace it because it is a recent and sometimes not well-understood concept. There is already a potential for automation and technology to take over the current production practices of garments, such as 3D printing [35]. 3D knitting and customization can reduce clothing waste by producing garments based on real-time demand and textile recycling presents an opportunity to incorporate design for easy disassembling and recyclability [35].

\subsection{Consumer Choices in the Fashion Industry}

Society in general, but young generations worldwide in particular, are not only drastically calling for a more sustainable future, but for having a future at all. It is undeniable that every individual should be considering radical lifestyle changes as potential solutions if one would like to stop or reverse the environmental destruction of the planet [36]. Currently society is facing an increasingly uncertain and competitive environment, where sustainability represents one of the most effective levers for attracting fashion consumers [7].

Consumer behaviors and attitudes are not constant but on the contrary they change over time [5]. Studies suggest that consumerism and unwise approaches to meeting consumption needs are problems deserving high priority [19]. However, according to Ciasullo et al. [7], market demand is changing towards a more sustainability conscious buying behavior. People are increasingly looking for products and brands that are more sustainable and that support their personal values. The authors state that consumer perceptions play an important role when it comes to behavior choices. The more informed people are about the importance of having ethical consumer practices, the more involved they feel and therefore the consumer behavior improves towards better practices. Mcneill and Moore [5] states that although consumers increasingly say that they care about unethical behavior and value sustainability, this attitude does not always translate to behavior, particularly in regard to fashion items. The authors even state that consumers are reluctant in implementing sustainable changes in their buying choices.

Furthermore, expectations play an important role when speaking of consumer choices. The higher the expectations about the product the more likely is that the consumer will buy it. However, some consumers buy products knowing about the low quality. This can occur if they have little time, if they are just locking for a product with those characteristics or if they want to compare it with a better product [7]. Gaps exist between customers consumption value expectations and their perceptions. Customer expectations are significantly higher than perceptions for almost all the items in the consumption value scale [9]. It is even possible that the consumer purchasing decisions are influenced by people they interact 
with or are surrounded by. This tend to happen more with young people who are still developing their interests and living habits. People buy certain products in order to be part of a specific group or social class or even take decisions because they want to belong to niche groups. Social influence is also an important aspect. People are often controlled by what they think others think. They want to maintain a specific reputation, and therefore they fall into social pressure. Consumers sometimes loose the notion of their own wills because they are focused on what they think is correct [7]. Consumption across many product sections is influenced by the human desire to express meanings about oneself and to create an identity, but this is perhaps particularly the case with clothing, which is constantly on display. Clothing is used to emanate meanings about the wearer to others and also to reinforce meanings to oneself [5]. The fast fashion trend has revolutionized the clothing industry over the past decade and changed the consumer attitudes to apparel consumption that led to a culture of impulse buying. This phenomenon is particularly salient amongst young female consumers, who have little awareness of the social impact of their fashion consumption but exhibit the highest levels of demand for new fashion items [5]. Greenpeace International (2019) states that the average consumer buys about $60 \%$ more clothing than over 15 years ago yet keeps them half as long. However, due to environmental concerns, more and more customers are showing a positive impulse towards green product purchase and even willing to pay relatively higher prices for them [9]. Ethical consumers are generally those who consider the wider impact of their consumption on other humans, animals or the physical environment. Nevertheless, some consumers are only concerned with personal wants and their own desire for acquisition, while others feel strongly that personal wants should always come second to the well-being of humanity and that consumption should only be driven by the need.

Furthermore, there is another extreme with some individuals feeling that the self should not be a focus in consumption, with the opinion that consumption is negative and propagated by capitalism and profit making. This type of consumers purchases minimal clothing and bases their fashion consumption generally on need [5]. Consumers have multiple identities and fashion is a symbolic reflection of personality, values, and feelings. By adopting and wearing certain garments, consumers translate meaning which is exchanged through social interactions and often mirrors how they wish others would feel or think about them. Consumers who are unhappy with their actual selves buy products that enhance their self-esteem and get them closer to their ideal self. Once a consumer has decided which self to show in a given situation, they will do what they believe is a symbolic reflection of that idealized self-identity such as wearing specific clothes and join certain groups. Additionally, most purchases are done with the assumption that a product will bring some type of change to the consumers [2] and the overall satisfaction with the product will impact repeated purchase decisions [9].

\subsection{Problem Statement}

As mentioned before, and as agreed between many authors, the broadness and complexity of the concept sustainability [11-13], hinders its implementation across any industry and creates a big challenge that requires the participation of many entities. As Vogt and Weber [13] stated, for a step forward in the sustainability implementation, sustainable culture must be created. That means a rediscovery of the ethics, patterns of consumption and an implementation of moderate living in societies and individuals as well as companies. This idea is very pertinent. In general, the education each human being has, makes it act in a certain way and the context where it lives plays a big role as well. If there is the ability to re-educate people towards sustainability, what it is, what it can be, how people can contribute, and if society and every single human has the knowledge to have better practices and habits, a big positive outcome can be created. One of the big problems one is able to identify is the lack of deep consciousness by consumers that is added by a lack of knowledge and missing consumer education $[2,5,6]$. There is a gap between the theory and the practice. This happens due to the fact that sustainability depends in so many ways 
from people, the future, the planet and what which human being and company is willing to do. The way people are willing to act now, will influence the future, and if people have the right mindset the consumption patterns can be reversed. For sure, the implementation of rules and policies by governments [15], can help to leverage sustainability practices and this aspect must be clearly developed in the future. The fact that fast fashion is strongly implemented as a mainstream business model where companies create a value proposition based on a mass production and an excessive consumption from buyers that are inside a fast paced loop [1,2], creates a barrier when trying to implement sustainability.

The fast fashion brands, due to its dimension, have a huge impact in the environment and societies. Even if there are many sustainable campaigns going one, that create an idea of evolution, many of this firms are implementing greenwashing with a consequent lack of transparency [18]. This aspect creates uncertainty in consumers and makes them insecure about the right way to act. At this point, one should say that reliability is a focal point in order to embrace sustainability as a whole. As one of the most important evolution, and a focal aspect, I lean towards the idea that a circular model implementation can help balance sustainability implantation, firms and consumers and create a win-win solution [26,32] substantiate this idea. Ciasullo et al. [7], state that consumers are already gaining a high perception on sustainability issues. However, there is the need to give consumers a voice and translate what they are doing into actual evidence. This will help to set the next steps for sustainability.

This literature review showed that the authors are all aligned in thoughts and ideas and that in some way each one of them complements the other. Space is created towards a gap in information from a concrete perspective of consumer behavior in the fashion industry and how sustainability is weighting in their usual habits. A game of expectations, reputation and reality is played by consumers with social pressure and awareness playing a big role in conclusion acquisition [7]. Information is key for development, and conscious moving forward is a demand for success.

\section{Materials and Methods}

The importance of research is undeniable when talking about knowledge improvement. Knowledge improvement characterizes evolution and deeper notion of various topics. Methodology is the tool that guides any study towards information acquisition and end results. For guiding this research towards its final conclusions and results, issues taken from literature are converted into research questions that are linked to specific research objectives. As a starting point, research issues identified by various authors in the literature, are fundamental for the strategy implementation. The research questions as well as the consequent research objectives, enable a delimitation and consequent guidance of the topics this research will cover. The Table 1 below enables a clear overview of the research instruments and objectives.

For the methodology of this study the qualitative research was chosen as a way of translating reality through reports of experiences of the subject under analysis. Through interviews one is able to take many conclusions on how the topic of sustainability in the fashion industry is affecting consumer choices. Interviews in this case enable concrete aspects listed by consumers in a reality representation, where facts and evidence are presented. It enables as well, a clear notion on how consumers are acting and what their future perspectives on the issue are. For successful interview results, it was firstly fundamental to elaborate an initial interview script resultant from the interconnection of research issues and research questions. With this first interview script, one was then able to do a pre-test. The pre-test was essential to understand and evaluate the objectivity of the questions, contrary to the analysis of the final interview script that is based on the analysis of the answers itself. For the pre-test, three random consumers were chosen. All the questions were done online via video call and were recorded in audio support for transcription and analysis. Timings were checked simultaneously to ensure an accurate time management. The pre-test was composed by fifteen questions, being the initial four a 
sample characterization, where aspects as gender, age, level of education and living area were asked. These aspects were not totally relevant for the analysis required in the pre-test but are then fundamental for the final script analysis.

Table 1. Research instrument and objective.

\begin{tabular}{|c|c|c|}
\hline \multicolumn{3}{|c|}{$\begin{array}{l}\text { Key Research Questions: } \\
\text { How does sustainability affect consumer choices in the fashion industry? }\end{array}$} \\
\hline Main Issues (Author, Year) & Research Question & Research Objective \\
\hline $\begin{array}{l}1 \text { Relevance of sustainability in the fashion } \\
\text { industry and the need for } \\
\text { consumer collaboration. } \\
\text { Todeschini et al. [34] }\end{array}$ & $\begin{array}{l}\text { RQ1: Is sustainability relevant enough for } \\
\text { consumers in their daily live in order to be the } \\
\text { center of their decisions? }\end{array}$ & $\begin{array}{l}\text { RO1: Collect information to understand in } \\
\text { which way sustainability in the fashion } \\
\text { industry is impacting consumer choices. } \\
\text { Integrate sustainability concerns as a main } \\
\text { topic in consumer decisions. }\end{array}$ \\
\hline $\begin{array}{l}2 \text { Consumers reluctance in adopting } \\
\text { sustainable changes to their } \\
\text { consumption choices. } \\
\text { Mcneill and Moore [5] }\end{array}$ & $\begin{array}{l}\text { RQ2: In which way is sustainability in the } \\
\text { fashion industry integrated into consumer } \\
\text { choices? What practices are } \\
\text { consumers adopting? }\end{array}$ & $\begin{array}{l}\text { RO2: Data collection for companies to further } \\
\text { understand consumer behavior in } \\
\text { present times. }\end{array}$ \\
\hline $\begin{array}{l}3 \text { Consumer behaviors and attitudes change } \\
\text { over time Mcneill and Moore [5] } \\
\text { People are changing their buying habits } \\
\text { towards products that support their } \\
\text { personal values. } \\
\text { Ciasullo et al. [7] }\end{array}$ & $\begin{array}{l}\text { RQ3: Are consumers changing/improving } \\
\text { their buying habits in the past years and do } \\
\text { they want to continue changing it in } \\
\text { the future? }\end{array}$ & $\begin{array}{l}\text { RO3: Prove that consumers have been } \\
\text { changing their buying habits towards } \\
\text { sustainability in the fashion industry. }\end{array}$ \\
\hline $\begin{array}{l}4 \text { Lack of knowledge about sustainability in } \\
\text { the fashion industry. } \\
\text { Lack of consumer education. } \\
\text { No understanding of slow fashion concept (in } \\
\text { contrast to fast fashion) } \\
\text { Legere and Kang [2] } \\
\text { Vogt and Weber [13] } \\
\text { Todeschini et al. [6] } \\
\text { Mcneill and Moore [5] }\end{array}$ & $\begin{array}{l}\text { RQ4: What barriers do consumers face when } \\
\text { speaking about sustainability in the } \\
\text { fashion industry? }\end{array}$ & $\begin{array}{l}\text { RO4: Offer companies and consumers a wider } \\
\text { notion of current barriers in sustainability } \\
\text { practices in the fashion industry. This will help } \\
\text { to guide companies and consumers to } \\
\text { possible solutions. }\end{array}$ \\
\hline
\end{tabular}

Source: Self-elaborated.

After the pre-test analysis and conclusion, some adjustments were made. In the sample characterization the last point of living area was changed for professional area because it came out to be an interesting aspect to be noted as the different participants of the interview had different professional backgrounds and this could enrichen the end conclusions and sharply influence the research.

Due to the broadness of the topic of sustainability and sustainability in the fashion industry [13], the research initially focused on too many research questions, which was not enabling a clear view of the direction we wanted to take for this research. Consequently, the questions in the pre-test took us to other areas of research, that being interesting and pertinent, were not the aim of this one specifically. So, some questions were adapted or even replaced by others more appropriate. One interesting adjustment was to create different questions for people who sustainability plays a relevant aspect and for those who are not implementing it in their consumer choices. This divides consumers in two types. The ones that are already implementing some kind of practices towards sustainability in the fashion industry and the ones that are not doing anything for now. This enables a deeper and more accurate comprehension of consumer behavior. The order of the questions was changed for a more coherent option, that enabled the creation of a guiding line. After all the adjustments made, the final script was elaborated.

The sample of this research is composed by 50 participants, that were chosen casually by saturation in a non-probabilistic purposive sample with the main objective to validate the model and the first findings. Regarding the sample size, it was based in the saturation principle for achieving an appropriate dimension where we did not have new data from the interviews, because we are in an introductory and qualitative study. Based on these limitations, we cannot generalize the findings. 
Having in mind the dimension of the research this method was the most appropriate as it is frequently taken to indicate that, on the basis of the data that have been collected or analyzed, further data collection is unnecessary [37]. It was important to create a diversified and heterogeneous sample with a wide range of ages, level of education and professional or study area. Due to the fact that it is covering consumer behavior that broadness is needed for a fair representation of individuals. All the interviews were done online and took place in January 2021. They were recorded in audio format, transcribed in text format and translated when needed, with fidelity to the speech, for further content analysis and conclusions. The interviews had an average duration of $20 \mathrm{~min}$. The software used for text mining and consequent data analysis was Kh Coder 3.

The Table A1 present in the Appendix A connects the interview questions with the research objectives and type of question.

\section{Results}

In this chapter one will analyze the information collected through the interviews made to consumers. The data analysis will enable a comprehension and an organization of information that will create a line of thought representing consumers ideas and actions towards sustainability in the fashion industry. This consequently will guide us to answer the research questions and the final conclusions and findings. As mentioned in the previous chapter the questions made in the interview were adapted for interviewers who have already sustainability as a concern when buying fashion items and for those who are not that conscious in their purchasing choices. The graphic below represents the existing division between consumers, when speaking about the relevance of sustainability in their purchasing choices of fashion items. For 30 interviewees, that corresponds to $60 \%$ of the sample, the concept of sustainability is a relevant aspect when purchasing choices are made, whereas for the other 20 interviewees, that correspond to $40 \%$ of the sample, sustainability is still not a relevant aspect when making buying choices in the fashion industry.

\subsection{Sample Characterization}

The sample characterization is an important aspect when analyzing data as it can deeply influence the final results and help in a wider comprehension of facts. The sample used for this research is focused in four main aspects: gender, age, academic qualification and professional or study area. As shown in Tables 2-6.

Table 2. Consumer Division.

\begin{tabular}{cl}
\hline Relevant & $60 \%$ \\
\hline Not Relevant & $40 \%$ \\
\hline Source: self-elaborated.
\end{tabular}

Table 3. Gender.

\begin{tabular}{cl}
\hline Female & $62 \%$ \\
\hline Male & $38 \%$ \\
\hline Source: self-elaborated
\end{tabular}

Table 4. Age range.

\begin{tabular}{ccc}
\hline $\mathbf{1 8 - 2 4}$ & $22 \%$ \\
\hline $\mathbf{2 5}-\mathbf{3 4}$ & $52 \%$ \\
\hline $\mathbf{3 5 - 4 4}$ & $4 \%$ \\
\hline $\mathbf{4 5 - 5 4}$ & $10 \%$ \\
\hline $\mathbf{5 5 - 6 4}$ & $6 \%$ \\
\hline $\mathbf{6 5 - o l d e r}$ & $6 \%$ \\
\hline
\end{tabular}


Table 5. Level of education.

\begin{tabular}{cc}
\hline Less than High School & $2 \%$ \\
\hline High School & $8 \%$ \\
\hline Bachelor & $28 \%$ \\
\hline Master & $60 \%$ \\
\hline Doctor & $2 \%$ \\
\hline
\end{tabular}

Source: self-elaborated.

Table 6. Professional/Study area.

\begin{tabular}{cc}
\hline Management & $28 \%$ \\
\hline Design and Art & $22 \%$ \\
\hline Law & $20 \%$ \\
\hline Finance & $6 \%$ \\
\hline Communication & $6 \%$ \\
\hline Engineering & $4 \%$ \\
\hline Sciences & $4 \%$ \\
\hline Health & $4 \%$ \\
\hline Hospitality and Tourism & $4 \%$ \\
\hline Education & $2 \%$ \\
\hline
\end{tabular}

Source: self-elaborated.

\subsubsection{Gender}

When speaking about the fashion industry, and although everybody in a general perspective is a consumer of clothes, shoes or accessories, it is an industry that tents to be associated to a more feminine consumption [5]. This was reflected in the collection of interviewees with 31 women corresponding to $62 \%$ of the sample, and 19 men corresponding to $38 \%$ of the collected sample.

\subsubsection{Age Range}

The sample complies interviewees from a wide age range, which enabled a more accurate sample representation. $22 \%$ are between 18 and 24 years old. The biggest portion are people between the 25 until 34 years old, continuing with $4 \%$ of the sample having between 35 and 44 . Following 10\% that has between 45 and 54 years old, 6\% between 55 and 64 years old and finally $6 \%$ is 65 years old or older.

\subsubsection{Academic Qualifications}

The chart below shows the division of the interviewees by academic qualification were $2 \%$ has less then high school, $8 \%$ completed high school, $28 \%$ has a bachelor's degree, the biggest portion has a master's degree, representing $60 \%$ of the interviewees and finally $2 \%$ has a doctoral degree.

\subsubsection{Professional/Study Area}

Regarding the professional/study area, as both are chosen because there are some of the interviewees that are still studying, $28 \%$ is from management, $22 \%$ from design and art, $20 \%$ from law, $6 \%$ from finance and $6 \%$ from communication. Additionally, $4 \%$ of the interviewees are from the areas of sciences, health or hospitality and tourism and finally $2 \%$ from education. 


\subsection{Text Mining}

With the 50 interviews conducted, one is able to identify and analyze differences and similarities between interviewees point of views that facilitate the creation of a general line of thought. Overall, the topic of sustainability is clearly implemented in every consumer's mind in different scales and through different behaviors. However, the concept associated to buying choices in the fashion industry, although it recognized relevance, it is still not being implemented by all of the interviewees. Several tools were used to analyze the data and to better understand the consumer's tendency. Later, all qualitative results will be related with the existing literature so that valid conclusions can be made.

\subsubsection{Word Frequency}

Using the word frequency list and the word cloud as initial tools for this research, one is able to easily visualize the most frequently words used by the interviewees that enable relevant conclusions. The Table 7 below and the Figure 2, give the introductory motto for the rest of the data analysis.

Table 7. Word Frequency List.

\begin{tabular}{|c|c|c|c|}
\hline & Word & POS/Conj. & Frequency \\
\hline 1 & Sustainability & Noun & 621 \\
\hline 2 & Fashion & Noun & 562 \\
\hline 3 & Industry & Noun & 396 \\
\hline 4 & Consumer & Noun & 256 \\
\hline 5 & Sustainable & Adj & 214 \\
\hline 6 & More & Adj & 188 \\
\hline 7 & Important & Adj & 184 \\
\hline 8 & role & Noun & 153 \\
\hline 9 & item & Noun & 152 \\
\hline 10 & practice & Noun & 139 \\
\hline 11 & Company & Noun & 138 \\
\hline 12 & Way & Noun & 135 \\
\hline 13 & Life & Noun & 118 \\
\hline 14 & Brand & Noun & 106 \\
\hline 15 & Concept & Noun & 92 \\
\hline 16 & Aspect & Noun & 89 \\
\hline 17 & Information & Noun & 87 \\
\hline 18 & Implementation & Noun & 85 \\
\hline 19 & Relevant & Adj & 80 \\
\hline 20 & Choice & Noun & 73 \\
\hline 21 & Motivation & Noun & 65 \\
\hline
\end{tabular}

Source: Self-elaborated based on KH Coder 3.

Due to the content and function similarity of both graphics shown above, the analysis will be done together. Considering the word frequency list, the general tendency of consumers is represented by single words that gain importance acting individually. All these words, despite having an important role independently, they relate with each other in a crucial way. Together, they have the ability to create a coherent line of thought that represents the interviewees answers as well as the main topic under analysis. This is the case of the words, sustainability, fashion, industry, consumer, important, role, implementation, motivation among others. One can observe that the word most frequently used is 
sustainability. This was an already expected fact, considering the main topic of this research. Despite being the focal point of this research, sustainability is undoubtedly a pertinent topic under analysis throughout industries and is raising the interest worldwide [18]. Generally, all respondents had the same position when asked about the relevance of sustainability in a general perspective in their lives. This was shown to be an important or even a fundamental aspect. That is in line with Brem and Puente-Díaz [36], that argued that people are aware of the topic of sustainability and are striving for a stop or reverse of current practices in order to assure a future. Words such as fashion and consumer are clearly frequent due to the general theme. Fashion is introduced in the context of the fashion industry and fashion consumption. Consequently, the word consumer appears as one of the most frequently used, as consumers are in the center of this research and are central to sustainability implementation in the fashion industry.

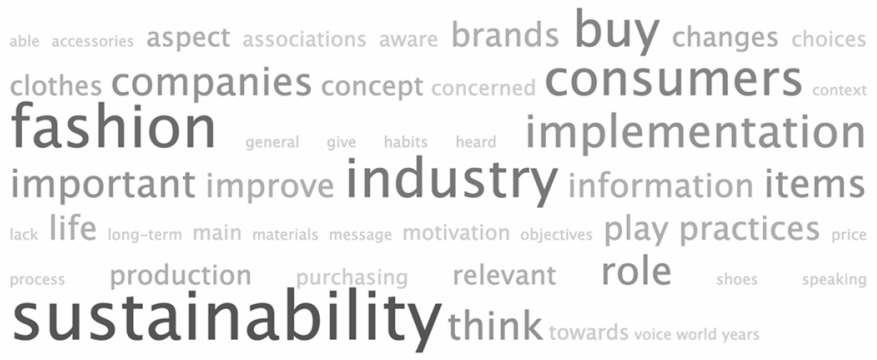

Figure 2. Word Cloud. Source: Tag Crowd.

Considering other important words present in the figures above, one can mention that the words "important" and "role" are clearly interconnected and represent the importance of consumers. This was unanimous between all interviewees. Consumers have the notion of their own potential for sustainability development and implementation. The word important is also related to the seriousness of the concept of sustainability in a larger scale and specifically in the fashion industry. The word "company" is also frequently used by all interviewees, this is due to the fact that companies are deeply intertwined in all that research, together with consumers they make the bridge to the industry. Simultaneously the word "information" appears as one of the most frequent words. Interviewees described information as a central point in the sustainability implementation when having to make buying choices. This idea is in coherence with Ciasullo et al. [7] that argues that the more informed consumers are the better choices consumers will make. At this point interviewees were divided in two groups the ones that are already informed about the topic of sustainability in the fashion industry and the ones were this information is still lacking. The word "relevant" appears as one of the most frequent and this is due to the actual relevance of the topic. Alone sustainability but together implemented in the fashion industry from the perspective of consumer behavior.

Going deeper in the word cloud, were the words most used are highlighted by a bigger size and consequently getting smaller as it loses it frequency, one can observed that words such as sustainability, fashion industry, consumer, relevant and information among others, are being repeated. That reinforces what has been said previously. However other important words can be noticed and are of extreme importance. This is the case of the word "concerned". Interviewees are generally concerned about sustainability in the fashion industry and agree that it is of extreme relevance, although not all of them is implementing reverse practices in favor of sustainability. This is in line with McNeill and Moore [5] and Biswas [9], who state that it is not always that concern about unethical behavior is actually transformed into a change of attitudes. When asked about their longterm objectives for sustainability implantation every interviewee showed motivation for various improvements or aspirations. The word "price" that shows up on the word cloud as important represents one aspect that was very popular between all respondents. The price factor was mentioned as a main barrier for having sustainability as a focal concern when 
buying fashion items. This proves again what Legere and Kang [2] said about consumers reluctance in adopting slow fashion due to barriers related to the higher price of sustainable fashion items.

\subsubsection{Words Association}

For deepen the analysis, word association is used in order to interconnect a specific word with the most frequent words associated. This is an interesting tool to create a bridge between concepts and ideas. The three main topics of this research, sustainability, fashion industry and consumer were chosen as object of analysis and are key for further conclusions. The Tables 8-10 represent the results from Kh coder.

Table 8. Sustainability Word Association.

\begin{tabular}{|c|c|c|c|c|c|}
\hline \multicolumn{6}{|c|}{ Sustainability } \\
\hline \multicolumn{6}{|c|}{ Result: } \\
\hline $\mathbf{N}$ & Word & POS & Unconditional & Conditional & Jaccard \\
\hline 1 & fashion & Noun & $446(0.453)$ & $263(0.518)$ & 0.3806 \\
\hline 2 & industry & Noun & $327(0.332)$ & $226(0.445)$ & 0.3711 \\
\hline 3 & important & Adj & $170(0.173)$ & $141(0.278)$ & 0.2626 \\
\hline 4 & role & Noun & $143(0.145)$ & $126(0.248)$ & 0.2400 \\
\hline 5 & way & Noun & $131(0.133)$ & $107(0.211)$ & 0.2011 \\
\hline 6 & not & $\mathrm{Adv}$ & $206(0.209)$ & $119(0.234)$ & 0.2000 \\
\hline 7 & life & Noun & $104(0.106)$ & $92(0.181)$ & 0.1769 \\
\hline 8 & concept & Noun & $87(0.088)$ & $82(0.161)$ & 0.1598 \\
\hline 9 & implementation & Noun & $84(0.085)$ & $80(0.157)$ & 0.1563 \\
\hline 10 & aspect & Noun & $83(0.084)$ & $69(0.136)$ & 0.1322 \\
\hline 11 & relevant & Adj & $76(0.077)$ & $64(0.126)$ & 0.1231 \\
\hline 12 & motivation & Noun & $61(0.062)$ & $59(0.116)$ & 0.1157 \\
\hline 13 & choice & Noun & $69(0.070)$ & $55(0.108)$ & 0.1054 \\
\hline 14 & context & Noun & $52(0.053)$ & $51(0.100)$ & 0.1002 \\
\hline 15 & long-term & Adj & $52(0.053)$ & $51(0.100)$ & 0.1002 \\
\hline 16 & objective & Noun & $50(0.051)$ & $49(0.096)$ & 0.0963 \\
\hline 17 & main & Adj & $57(0.058)$ & $49(0.096)$ & 0.0950 \\
\hline 18 & association & Noun & $54(0.055)$ & $48(0.094)$ & 0.0934 \\
\hline 19 & kind & Noun & $39(0.040)$ & $33(0.065)$ & 0.0642 \\
\hline 20 & nowadays & $\mathrm{Adv}$ & $33(0.034)$ & $29(0.057)$ & 0.0566 \\
\hline
\end{tabular}

Source: Self-elaborated based on KH Coder 3.

Initially, it is relevant to explain the content of each table that will be presented in this part. In the first column we can look at the words that are mostly associated with the word we searched for, in this specific case "sustainability". The column named unconditional identifies the number of times the word was used in the interviews. The conditional column refers to the number of times the word was associated with the word under search and finally the last column named Jaccard refers to a coefficient that has no relevance for this research. When identifying the two most popular words interconnected with sustainability, one identifies "fashion" and "industry". This can be explained by the fact that this research is specifying the concept of sustainability in the fashion industry. One of the first questions asked in the interview was about the relevance of the concept of sustainability in the interviewee's lives. The first question was in this case in a general perspective in order 
to introduce the topic. Broadly, almost all respondents in a general perspective answered that sustainability plays an important role in their lives. Some implementing it since an early age other more recently but concepts such as recycling, and waste management often came up. That is why words such as "important", "implementation", "relevant" and "motivation" appear as highly associated with sustainability. This clearly represents the relevance of sustainability among the interviewees and that sustainability is gaining increased awareness and popularity. This goes in line with Ciasullo et al. [7], that say that sustainability is increasingly taken an outstanding role. Not only consumers realize that sustainability is an important issue, but they also feel motivated to implement it as a main objective in their lives. Concrete practices will further be developed.

Table 9. Fashion Industry Word Association.

\begin{tabular}{|c|c|c|c|c|c|}
\hline \multicolumn{6}{|c|}{ Fashion Industry } \\
\hline \multicolumn{6}{|c|}{ Result: } \\
\hline $\mathbf{N}$ & Word & POS & Unconditional & Conditional & Jaccard \\
\hline 1 & sustainability & Noun & $508(0.516)$ & $221(0.715)$ & 0.3708 \\
\hline 2 & consumer & Noun & $212(0.215)$ & $105(0.340)$ & 0.2524 \\
\hline 3 & sustainable & Adj & $195(0.198)$ & $82(0.265)$ & 0.1943 \\
\hline 4 & relevant & Adj & $76(0.077)$ & $57(0.184)$ & 0.1738 \\
\hline 5 & aspect & Noun & $83(0.084)$ & $55(0.178)$ & 0.1632 \\
\hline 6 & association & Noun & $54(0.055)$ & $47(0.152)$ & 0.1487 \\
\hline 7 & main & Adj & $57(0.058)$ & $47(0.152)$ & 0.1473 \\
\hline 8 & choice & Noun & $69(0.070)$ & $48(0.155)$ & 0.1455 \\
\hline 9 & important & Adj & $170(0.173)$ & $60(0.194)$ & 0.1432 \\
\hline 10 & way & Noun & $131(0.133)$ & $55(0.178)$ & 0.1429 \\
\hline 11 & implementation & Noun & $84(0.085)$ & $48(0.155)$ & 0.1391 \\
\hline 12 & change & Noun & $54(0.055)$ & $43(0.139)$ & 0.1344 \\
\hline 13 & role & Noun & $143(0.145)$ & $52(0.168)$ & 0.1300 \\
\hline 14 & company & Noun & $127(0.129)$ & $48(0.155)$ & 0.1237 \\
\hline 15 & item & Noun & $144(0.146)$ & $48(0.155)$ & 0.1185 \\
\hline 16 & motivation & Noun & $61(0.062)$ & $36(0.117)$ & 0.1078 \\
\hline 17 & habit & Noun & $50(0.051)$ & $30(0.097)$ & 0.0912 \\
\hline 18 & last & Adj & $39(0.040)$ & $29(0.094)$ & 0.0909 \\
\hline 19 & buying & Noun & $54(0.055)$ & $30(0.097)$ & 0.0901 \\
\hline 20 & context & Noun & $52(0.053)$ & $29(0.094)$ & 0.0873 \\
\hline
\end{tabular}

Source: Self-elaborated based on KH Coder 3.

Another important aspect is the fact that the word "nowadays" and "long-term" is associated to sustainability. This reveals that the respondents think about the concept in a present time and are aware of its urgency but are looking forward to improving it in the future, creating more and new objectives. This is a very pertinent line of thought and emphasizes McNeill and Moore's [5] idea that sustainability improvements are only achievable in the long term if consumers support it, by making conscious choices.

This table has many similarities with the previous one. The two most frequently used words associated to fashion industry were "sustainability" and "consumer". Again, this is due to the main thematic of this research and was totally predictable. Sustainability as the main issue and consumers together with companies, as the main players. When speaking about sustainability specifically in the fashion industry unanimously everybody identifies this topic of an extreme relevance. However, consumer practices and motivations diverge, 
the importance is undeniable. Words such as "relevant", "important" and "motivation" appear as frequently related to fashion industry. Questions in the interview were asked to understand what the interviewees motivations are, or which one are lacking. In general, respondents agree that they care about sustainability in the fashion industry because they have a general concern for sustainability. The lacking motivation is generally related to lack of information, accessibility and transparency. It is notorious between all interviewees that a transformation must occur. This explains the word "change". Change of the fashion industry, change of consumer practices, change of company's value proposition, change of rules, change of ethical-cultural orientation. One can say that generally the interviewees agree with $[13,21]$ by saying that innovation through a multi-dimensional approach is needed and that sustainability in practice requires changes in practices, behaviors and ways of thinking. Consumers make a lot of associations when speaking about the fashion industry by responding to one of the questions present in the interview. And that's why the word "association" appears in the table. Respondents in a general perspective are aware that the fashion industry is one of the most polluting industries in the world with the highest negative impact on the planet, due to chemicals use, excessive water consumption and massification in waste among other aspects. This goes in line with [2,3]. Although consumers play a big role in this research and are even central, companies play an important role as well. The word "company" is therefore obviously associated to the fashion industry. Companies are an integral part of the fashion industry. They are the one, that due to its dimension are more exposed when speaking about sustainability implementation.

Table 10. Consumer Word Association.

\begin{tabular}{|c|c|c|c|c|c|}
\hline \multicolumn{6}{|c|}{ Consumer } \\
\hline \multicolumn{6}{|c|}{ Result: } \\
\hline $\mathbf{N}$ & Word & POS & Unconditional & Conditional & Jaccard \\
\hline 1 & company & Noun & $127(0.129)$ & $96(0.453)$ & 0.3951 \\
\hline 2 & fashion & Noun & $446(0.453)$ & $143(0.675)$ & 0.2777 \\
\hline 3 & industry & Noun & $327(0.332)$ & $113(0.533)$ & 0.2653 \\
\hline 4 & important & Adj & $170(0.173)$ & $77(0.363)$ & 0.2525 \\
\hline 5 & role & Noun & $143(0.145)$ & $70(0.330)$ & 0.2456 \\
\hline 6 & implementation & Noun & $84(0.085)$ & $51(0.241)$ & 0.2082 \\
\hline 7 & change & Noun & $54(0.055)$ & $45(0.212)$ & 0.2036 \\
\hline 8 & way & Noun & $131(0.133)$ & $57(0.269)$ & 0.1993 \\
\hline 9 & sustainable & Adj & $195(0.198)$ & $64(0.302)$ & 0.1866 \\
\hline 10 & item & Noun & $144(0.146)$ & $49(0.231)$ & 0.1596 \\
\hline 11 & world & Noun & $40(0.041)$ & $33(0.156)$ & 0.1507 \\
\hline 12 & advice & Noun & $32(0.033)$ & $31(0.146)$ & 0.1455 \\
\hline 13 & able & Adj & $46(0.047)$ & $32(0.151)$ & 0.1416 \\
\hline 14 & message & Noun & $35(0.036)$ & $30(0.142)$ & 0.1382 \\
\hline 15 & voice & Noun & $36(0.037)$ & $30(0.142)$ & 0.1376 \\
\hline 16 & brand & Noun & $87(0.088)$ & $27(0.127)$ & 0.0993 \\
\hline 17 & shoe & Noun & $13(0.013)$ & $11(0.052)$ & 0.0514 \\
\hline 18 & key & Adj & $12(0.012)$ & $10(0.047)$ & 0.0467 \\
\hline 19 & clothes & ProperNoun & $9(0.009)$ & $9(0.042)$ & 0.0425 \\
\hline 20 & accessory & Noun & $11(0.011)$ & $9(0.042)$ & 0.0421 \\
\hline
\end{tabular}


Finally, the word "implementation" is relevant, as it shows that the interviewees are already implementing some kind of practices towards the improvement of sustainability in the fashion industry and a minority is not implementing it yet but is willing to do it in the future.

The next table shows the connections with the word "consumer".

Consumers are not only part of one of the focal points of this research but are also undeniably part of the implementation of sustainability in the fashion industry. The table above, Table 10, similarly to the previous ones has the same kind of words associated to the words previously searched.

Firstly, it is important to mention that the most associated word to "consumer" is "company". That makes a lot of sense, as consumers and companies are the key elements. Consumers and companies together have the ability to change market practices. Consumers are directly connected to the companies and to the industry, they set the pace. Demand determines supply and frequently supply determines demand. In this sequence the word "key" appears in the table. Also relevant to mention is the word "important" followed by "role". Consumers have definitely an important role in the sustainability implementation through their general practices towards this issue and their buying options and generally all interviewees agree with that idea. Again, interviewees recognize a need for change. The word "change" appears and this represent the change in consumer behaviors and attitudes over time [5].

When speaking about consumers, it was notorious trough almost all interviewees that they were aware that the fashion industry is one of the industries with a bigger need in terms of sustainability improvement. However not all of them is implementing sustainable practices in their buying choices. At this point a division was made. Although that division is present between consumers this is not represented in the table above.

Finally, comparing all three tables mentioned above, one can observe a very high similarity of words between all of them, this is due to the fact that all these three subjects were always threated together and therefore are closely intertwined. In this case, all three depend on each other. Words such as "important" appear in all three tables what makes us understand the relevance of the theme and elements under analysis. Word association enables to understand the frequency of words by segments. The next graph will enable a general interpretation of words represented. Together they symbolize the whole perspective.

Although, it is interesting to analyze specific words and words association individually, the Figure 3 enables a general view of the whole subject under analysis, where one can analyze many aspects simultaneously. Further questions of the interview can be covered at this point.

Starting by the motivation of the consumers interviewed. Generally, consumers are motivated to improve their practices in their buying choices. Some of them are already implementing it with various practices and other are still not able to do so. Many interviewees argued that although they are motivated to improve and implement sustainability in their lives, they still do not know how to do so. In this context words such as "improve", "motivation" appears represented above. This is explained by the lack of knowledge. This idea is in accordance with Vogt and Weber [13] and affirms that the topic of sustainability in a deeper sense is not understood by people in general and is also in line with McNeill and Moore [5], who specify the lack of knowledge about sustainability implemented in the fashion industry. That sustainability generally and specifically in the fashion industry is a relevant aspect for the interviewees and that consumers are essential in its implementation we already proved from the previous analysis. Words such as "important", "change" and "act sustainable" appear again to emphasize that idea. This was notorious in the answers given throughout the interview. The word "relevant" present in the graph reveals the importance of the topic. 


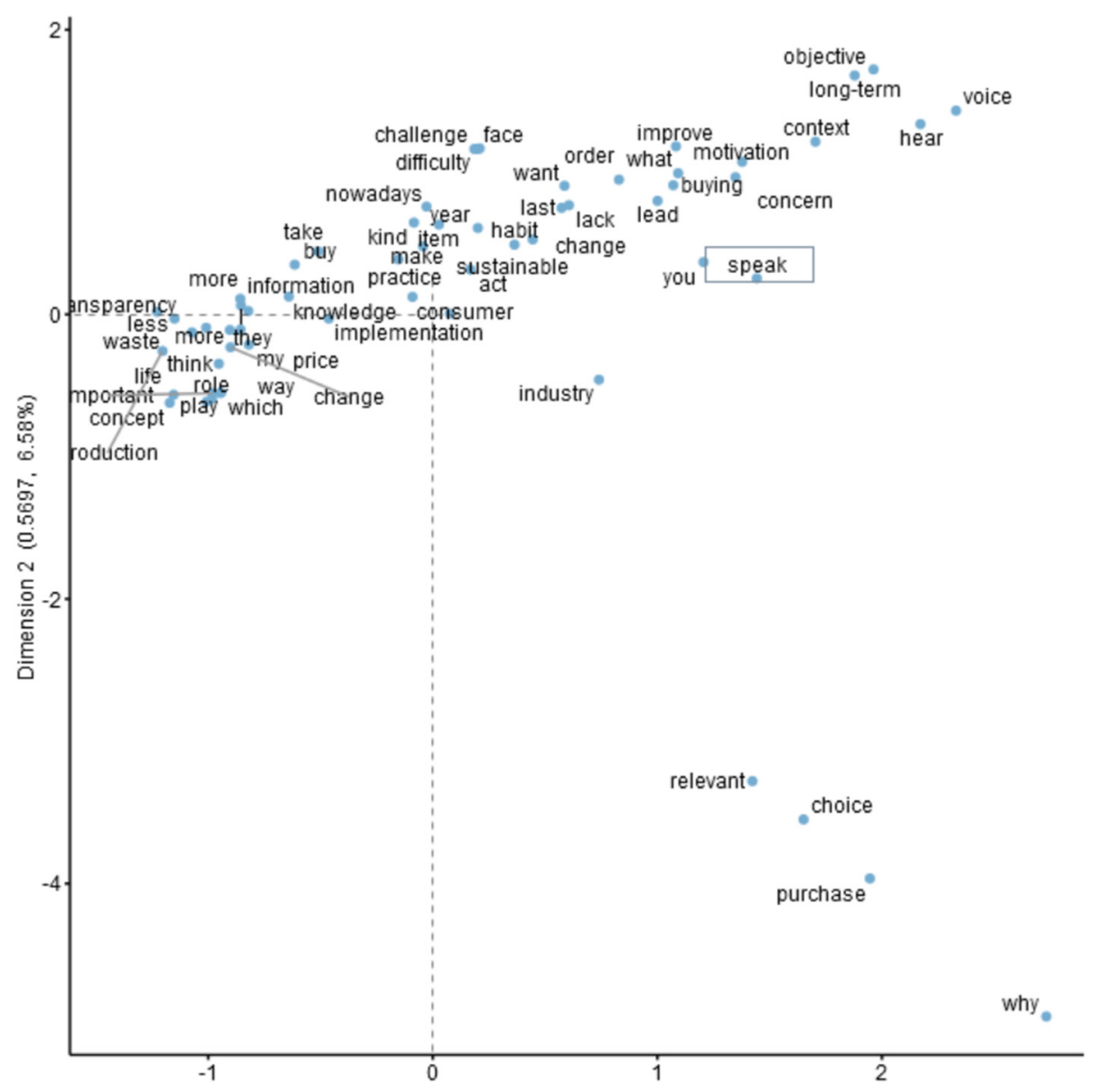

Figure 3. Correspondence Analysis of words. Source: KH coder 3.

Finally, moving forward to the next relevant aspect, when questioned about the challenges and difficulties that consumer interviewed face when they try to implement sustainability in their buying choices in the fashion industry, again one of the most popular answer was lack of information, knowledge, the price factor was also mentioned as a barrier and transparency as a missing factor. All that aspects come to light in the graph above with the word's "knowledge", "information", "price" and "transparency". Already many authors stated that sustainability is a complex and open concept that is always in continuous evolution [13]. Consequently, it is difficult to define accurately. In fact, that was also reflected in the answers given by some of the interviewees. The concept generally and implemented in the fashion industry lacks information. People are willing to make more conscious buying choices; however, they do not know exactly how. The concept is mostly not well understood [2]. Comparing the words present in this graph and in the tables present in the previous part one can identify similarities in words. This is the case of important, industry, motivation, long-term, objective, implementation and nowadays. This reveals a strong consistency on the interviewee's answers.

Starting by analyzing the Bigram represented by Table 11, word sequences such as "I would", "I am", "I think" and "I have" appear with a significant frequency. This occurs due to the fact that the interviews were addressed personally to each one of the consumers interviewed. The interviewees answered in the first person to the questions made, and shared they thoughts, concerns, personal experiences, practices and objectives.

Additionally, one can create a line of thought with the word sequence "I would", "would like", "want to" and "try to". This clearly represents the willingness to change. The interviewees showed throughout the interview concern with the topic of sustainability and the majority is clearly making an effort in order to improve their buying habits. Interviewees reveled that they have sustainability objectives in a long-term. They are making, an 
effort to be more informed and to implement their knowledge to make conscious choices and want to continue making it in the future. Many interviewees mention consciousness as a central tool for the improvement of their behavior. Due to its nature the rest of the word conjugation are not useful for this analysis.

Table 11. Bigram.

\begin{tabular}{ccc}
\hline No. & N-Gram & Frequency \\
\hline $\mathbf{1}$ & in the & 157 \\
\hline $\mathbf{3}$ & fashion industry & 112 \\
\hline $\mathbf{4}$ & the fashion & 108 \\
\hline $\mathbf{5}$ & it is & 99 \\
\hline $\mathbf{6}$ & of the & 90 \\
\hline $\mathbf{7}$ & sustainability in & 89 \\
\hline $\mathbf{8}$ & of sustainability & 79 \\
\hline $\mathbf{9}$ & i would & 76 \\
\hline $\mathbf{1 0}$ & i am & 69 \\
\hline $\mathbf{1 1}$ & i think & 66 \\
\hline $\mathbf{1 2}$ & in my & 64 \\
\hline $\mathbf{1 3}$ & would like & 62 \\
\hline $\mathbf{1 4}$ & like to & 60 \\
\hline $\mathbf{1 5}$ & to be & 60 \\
\hline $\mathbf{1 6}$ & want to & 58 \\
\hline $\mathbf{1 7}$ & about the & 58 \\
\hline $\mathbf{1 8}$ & is a & 57 \\
\hline $\mathbf{2 0}$ & on the & 56 \\
\hline
\end{tabular}

Source: Self-elaborated based on N-Gram generator.

Moving to Table 12 where trigrams can be observed, one can identify many similarities with the previous one. Examples of that are the trigrams: "I would like", "would like to", "I try to", "I want to" and "I think about", that go in the same line of thought than the previous bigrams mentioned. All the bigrams and trigrams selected in this table are therefore in some way interconnected. One of the main objectives of the interview was to understand the relevance of sustainability in the fashion industry in consumers lives, as well as understand how this aspect is influencing them and their buying habits. In the sequence of answering to their current practices, the trigram "when I buy" appears. The concept of sustainability is extensive. In this research a focus on sustainability in the fashion industry is specifically made, where consumers were asked about their concrete notions on the topic. The trigram "fashion industry is" confirms the previous affirmation. Although, in general consumers had some notions on the topic, it turned out to be vague and complex. Consequently, it did not give much relevance for further conclusions. With the trigram "an important role", the relevance of consumers in the process of sustainability implementation as well as the importance of the issue of sustainability is reinforced. 
Table 12. Trigram.

\begin{tabular}{ccc}
\hline No. & N-Gram & Frequency \\
\hline $\mathbf{1}$ & the fashion industry & 102 \\
\hline $\mathbf{3}$ & in the fashion & 78 \\
\hline $\mathbf{4}$ & sustainability in the & 62 \\
\hline $\mathbf{5}$ & i would like & 62 \\
\hline $\mathbf{6}$ & the concept of & 39 \\
\hline $\mathbf{7}$ & i try to & 38 \\
\hline $\mathbf{8}$ & Concept of sustainability & 37 \\
\hline $\mathbf{9}$ & would like to & 34 \\
\hline $\mathbf{1 0}$ & i want to & 34 \\
\hline $\mathbf{1 1}$ & i think about & 34 \\
\hline $\mathbf{1 2}$ & an important role & 31 \\
\hline $\mathbf{1 3}$ & in my life & 31 \\
\hline $\mathbf{1 4}$ & like to see & 26 \\
\hline $\mathbf{1 5}$ & important role in & 23 \\
\hline $\mathbf{1 6}$ & about sustainability in & 23 \\
\hline $\mathbf{1 7}$ & of sustainability in & 23 \\
\hline $\mathbf{1 8}$ & think about the & 20 \\
\hline $\mathbf{2 0}$ & i am not & 19 \\
\hline
\end{tabular}

Source: Self-elaborated based on N-Gram generator.

\subsubsection{Text}

After inserting all the interview content in $\mathrm{KH}$ coder, the resultant mind map can be observed above in Figure 4. In this diagram, one is able to analyze the relation between concepts and line of thoughts presented by consumers interviewed. First of all, the diagram is divided into small subgraphs, that clearly represent the questions done in the interview. These will be analyzed individually, enabling then a final comparison and interconnection.

\section{Correlation, Mind Mapping and Cluster Analysis}

Starting by analyzing subgraph 01 , that is composed by four words that are undoubtedly connected to the question related to motivation. What is motivating interviewees to have sustainability in mind when they are making buying choices or, from another perspective, what kind of motivation is lacking. The leading motivation for those who are already implementing it, is the general context of sustainability. These interviewees referred that the fact that they are concerned about sustainability in a general perspective, complying recycling practices and consumerism reduction made them aware of sustainability implemented in the fashion industry. On the other hand, the ones who the motivation is still lacking, justify it buy low levels of knowledge, information or even awareness about the topic. Additionally, the factor price was frequently mentioned as a lacking motivation.

Subgraph 02 is composed by three words: "kind", "nowadays" and "take", that although not being very explicit, refers to which kind of practices people are implementing nowadays in their buying choices in the fashion industry. This question was only addressed to $60 \%$ of the interviewees, being that the percentage of respondents that has sustainability as a relevant aspect in their buying decisions. 


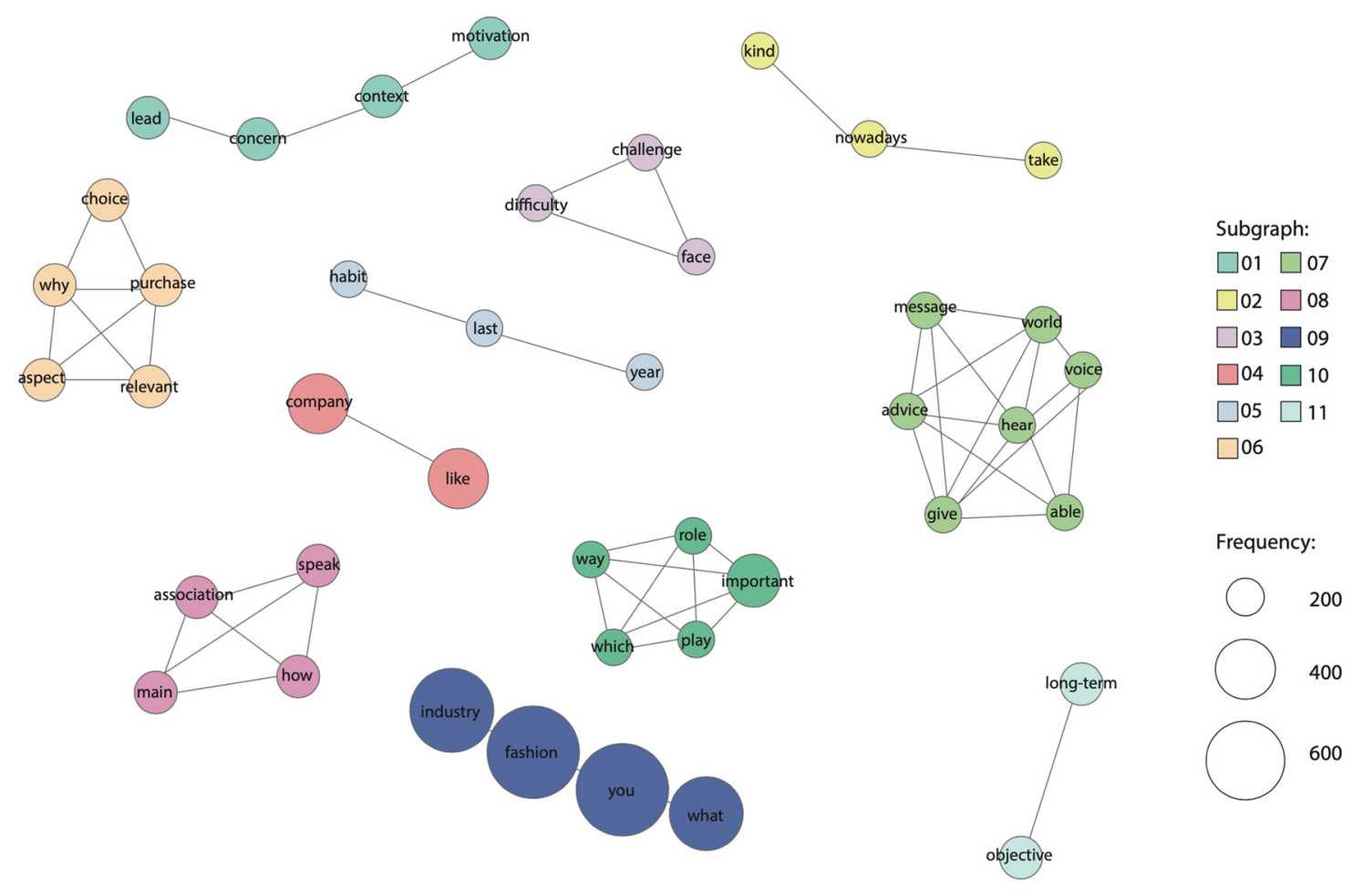

Figure 4. Text Correlation and Mining Mapping. Source: Self-elaborated based on KH Coder.

The most common practices between interviewees were reducing consumption in general, buying the strictly needed and investing in classical pieces with quality that last a lifetime. Also mentioned was buying from small brands and independent fashion designers instead of big groups, consequently eliminating the consumption of fast fashion. Some consumers also buy second hand and vintage. Consumers interviewed mentioned that they try to inform themselves before they buy a specific item. They pay attention to the labels and research about the fabric composition and production origin. In general interviewees specified that they avoid impulse purchases. The other $40 \%$ although recognizing its relevance are still reluctant in adopting changes to their consumption. This conclusion confirms McNeill and Moore's [5] statement. The question of which challenges and difficulties consumers are facing when trying to buy sustainable items in the fashion industry is represented by subgraph 03. Interviewees named some aspects such as accessibility, transparency, lack of information and price. This topic will be developed further on. Not only consumers but also companies have an important role in this research. Consumers were unanimous when saying that companies and consumers together have the power to make a significant change. This is notorious in subgraph 04 .

Moving forward to subgraph 05, where we can find three words, one can assume the connection to the question were interviewees answered if they have improved their buying habits towards sustainability in the last years. The most common answer was yes. This is in line with McNeill and Moore's [5] idea that consumer behavior changes over time. That sustainability is a relevant aspect in the consumer interviewed one could already conclude in the analysis made before. At this point one is able to confirm in subgraph 06 this affirmation. This addresses also to the question were respondents answered if sustainability is a relevant aspect in their buying choices.

Subgraph 07 is the most complex subgraph present in this diagram, being composed by many words. This represents the last question present in the interview that asked interviewees to leave a message to all fashion consumers and companies in the world. The answers in this part diverge immensely, however, they are not able to be decodified in this diagram. 
Going deeper into subgraph 08, one can recognize the question where interviewees were supposed to share their main associations when speaking about the fashion industry. Overall, this is intended to bring to life how consumers are looking at the fashion industry and their practices in current times.

When analyzing subgraph 09 , is composed by four words: "industry", "fashion", "you", "what". Due to the dimension of its frequency, one can conclude that these are the words mostly used. The fashion industry as a main theme, and the questions addressed personally to each one of the consumers interviewed.

The subgraph 10 represents the question where interviewees were asked about the importance of consumers in the implementation of sustainability. All of them agreed that consumers play an important role.

Lastly, the subgraph 11 shows that consumers have long- term objectives towards sustainability implementation, the majority is looking forward to getting more information and knowledge on the topic. The words "long-term" and "objective" prove the previous affirmation. This diagram enabled a general view of the interview content; however, some details were missing that one will try to address in the following section.

\subsubsection{Text Clustering}

Text clustering is one of the most important text mining techniques. Clustering a text can play an important role for an adequate document organization, summarization, topic extraction and information retrieval [38]. This technique will be used as the last tool for the chapter of data analysis.

It is possible to cover many aspects present in the interview with the Figure 5, that represents a text clustering. More than in the mind map, here we can extract some extra relevant information. The interview was addressed to consumers with the clear notion that not everybody is having sustainability into consideration when buying fashion items. This was actually confirmed. Factors such as age range, area of study or professional area play a big role, however, it mostly depends on the context or even social-cultural background people are living in [15]. In the interview many topics were discussed. Understanding consumers motivations, was interesting for further conclusions. At this point questions diverged between the motivations that are making people choose for sustainable options and the motivations that are lacking. In general, all interviewees identified some "challenges" and "difficulties", two of the words present in the figure above in the pink section. Respondents tent to talk about the lack of transparency. This confirms the idea that the fashion industry is subject to negative stereotypes [2] but also the feeling of skepticism towards sustainable practices present among consumers [26]. These aspects were notorious in some of the interviews made. Furthermore, words such as "information", "more" and "knowledge" appear again as relevant words. This covers the general context or motivation that is making the interviewees do not implement sustainability in their buying choices in the fashion industry. Vogt and Weber [13], mentioned the lack of knowledge between consumers. This aspect was mentioned by the consumers interviewed. As already said before the aspects such as brand information and their sustainable practices is lacking. Transparency towards consumers about materials, production and value chain are missing.

Consumers interviewed revealed to have concern about sustainability in general and even their buying habits were proved, with the answers given, to have improved in the last years and there is still room for improvement. This is due to the increasing interest in the topic of sustainability [18]. Words such as "buying", "habit", "last", "year" are present in the figure above to give what was said before constancy. Consumers have differentiated long term objectives towards sustainability in the fashion industry, some of them want to be less consumerism and buy less but with better quality. Other practices such as abandoning fast fashion were frequently mentioned. Although other interesting perspectives were given by some of the interviewees, due to the lack of expression in terms of frequency, these are not notorious in the graphs and tables shown above. 

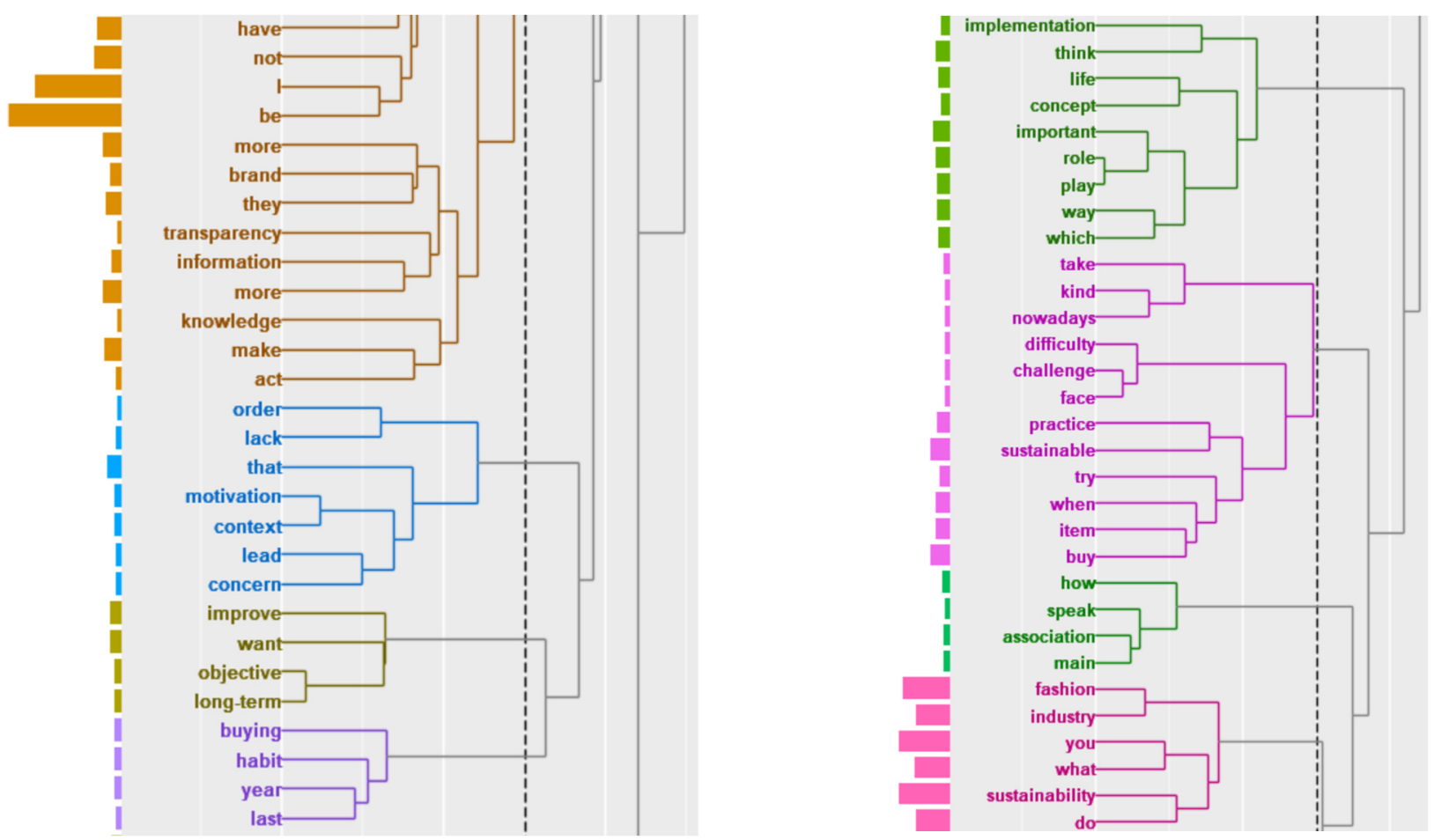

Figure 5. Text Clustering. Source: KH Coder 3.

\section{Discussion}

The results will be discussed in this chapter and confronted with existing literature, enabling confirmations, evolution and new discoveries.

Starting by the first research question "Is sustainability relevant enough for consumers in their daily live in order to be the center of their decisions?", that was clearly answered by all 50 consumers interviewed. The relevance of the topic of sustainability in a general perspective, as well as in the fashion industry and the crucial role of consumers in its implementation and evolution its undeniable. Todeschini et al. [6] already mentioned it and the interviewees confirmed it by demonstrating a clear awareness on the importance of this issue and their key role. However, and although the recognition of its pertinence, consumers were divided in two main groups. The ones that sustainability already is impacting their buying choices in the fashion industry, corresponding to $60 \%$ of the interviewees. And on the other hand, the ones that although recognizing the relevance of the topic under analysis, are still not implementing any changes in their buying choices. This group consists of $40 \%$ of the consumers interviewed. This part of the interview confirmed McNeill and Moore's [5] idea that, although consumers affirm that they care about sustainability, this is not translated into actual practices. The majority of the interviewees has a positive behavior towards sustainability implementation in the fashion industry. This is not only related to their own predisposition and interest in the topic but also on the education and groups they are insert in. It is also important to mentioned that gender, age range and professional or study area influenced the results. Younger generations, in a general perspective, are better informed. This is not only due to the fact that sustainability is a recent topic, but also due to the evidence that more and more sustainability is implemented in younger generations education. This is in line with Vogt and Weber [13] when they characterize sustainability as a new ethical-cultural orientation and with Brem and Puente-Díaz [3] when they conclude that younger generations are very concerned with their future, going against the consumption of fast fashion items; meaning there exists a conflict between consumers [19].

At this point, it is important to mention that the major tendency is towards the positive change of consumers behavior and perception and there is a dominant trend 
for improvement. This goes against Ciasullo et al. [7] idea that consumers attach little relevance to the importance of brand sustainability and that they guide themselves on the basis of their expectations and society. This could be actually the case of some consumers interviewed, nevertheless what the general tendency shows is a common concern and awareness on the topic. Having consumers aware, will enable that improvements occur more rapidly. Consumers that are not implementing sustainability in their buying choices in the fashion industry yet, are the ones that should be analyzed deeper due to their potential for improving in the future. Changing their perceptions is the challenge companies should work on. Understanding what is lacking in order for them to act is crucial to make them change.

With regard to the second research question "In which way is sustainability in the fashion industry integrated into consumer choices? What practices are consumers adopting?" the analysis showed a variety of aspects. Although not every consumer interviewed was able to share their sustainable practices towards the fashion consumption, and this information was not very clear in the previous chapter, it is relevant to share that the majority of the consumers is trying to reduce consumption in a general perspective and eliminating the consumption of fast fashion, giving preference to timeless classical pieces that last a lifetime, instead of trendy items. This does not mean consumers are eliminating totally fast fashion items, but it shows a willingness to do so. Although, the concrete leaning for more sustainable choices, fast fashion comes up to be still a very present business model. This confirms Legere and Kang [2] idea on the strong implementation of fast fashion. The interviews also showed that consumers are changing their lifestyle towards a more minimalist approach. The general tendency showed that consumers are avoiding impulse purchases and that they are making an effort to just buy the strictly needed. It is important to mention that interviewees showed concern in the composition of the items they buy, being careful when it comes the materials the pieces are made of as well as the location where they are produced.

Referring to the third research question "Are consumers changing/improving their buying habits in the past years and do they want to continue changing it in the future?", the answer between all interviewees was positive. Consumers have generally been changing their behaviors and attitudes over the last years. Which consequently confirms Mcneill and Moore [5] idea. The majority is not only changing their buying habit, but also willing to improve in the future. Having many expectations and objectives in the long-term for sustainability implementation and consequently in the fashion consumption as well. This came out to be a cross cutting concern. As sustainability in general is gaining an increased awareness and interest [18], consumers extent their perception to a variety of aspects in their lives, trying to inform themselves of all the aspects they can improve in a general term. This goes in line with Ciasullo et al. [7] that mentioned that people are changing their buying habits towards products that support their personal values. From the interviews and the consequent data analysis one could identify a macro tendency towards change. Change of perception, change of habits, change of requirements, change of perspectives. In this case change is deeply intertwined with evolution. The tendency is towards the evolution, not only because of the need, but also because of the general human evolution. This is a relevant aspect for the companies. Knowing that consumers are willing to change, enables to gain more confidence to insert sustainability in their value propositions. However, a lack of knowledge and information between interviewees is present which is an integral part of the barriers consumers face when speaking about this issue. Confirming McNeill and Moore [19] theory.

At this point, it is pertinent to insert the fourth and last research question, "What barriers do consumers face when speaking about sustainability in the fashion industry?". This research question comes out to be of extreme relevance, enabling the guidance through many lines of thoughts and consequent capacity of changes from part of the companies. In the interviews the respondents that are already implementing sustainability as a concern when buying fashion items, identified some barriers they are facing. Namely lack of information, knowledge, transparency, accessibility, visibility, communication, and they 
even mentioned that they are confronted with substantial higher prices and little offer. Consumers revealed that for acting sustainable they have to search intensively by their own. Making exhaustive research is something that is done by many of the interviewees. This shows that information is still not of easy access. There is a clear lack of knowledge that is hindering the evolution of sustainability in the fashion industry. This is also related to the existing gaps between consumers expectations and perceptions, an important aspect for companies to have in mind [2]. The same barriers that people face when trying to implement sustainability in their buying choices are almost the same motivations that people that do not act sustainable in their purchasing choices are lacking. Although wanting to do so, they do not have information. The information does not come to them easily and they are not predisposed to search for it. The barriers identified by consumers will enable companies to have a clear and realistic notion of consumers point of view which enables improvement.

After analyzing data and results were discussed some key findings will be point out:

- Consumers are aware of the general relevance of the concept of sustainability and specifically when implemented in the fashion industry. It is a cross-cutting concern;

- There are two types of consumers. Those that see sustainability as a central aspect when making buying choices ( $60 \%$ of the consumers interviewed) and those that, although recognizing its relevance, are still not implementing it (40\%);

- Consumers that do not assign enough relevance to the topic to change their habits are lacking motivation, education, information, awareness and knowledge;

- The consumers that do not implement sustainability in the fashion industry in their buying choices, are the ones with the most potential for a change. They are the ones companies should focus on the most;

- Generally, consumers have been improving their buying habits in terms of sustainability in the past years with more practice and more awareness;

- Broadly, every interviewee is willing to improve their buying behavior, in terms of sustainability in the fashion industry, in the future;

- When speaking about current practices, consumers are adopting a less consumeristic approach: buying the strictly needed, with higher quality, avoiding fast fashion items and supporting small local brands and independent designers;

- Consumers identify a big lack of knowledge as a principal problem when speaking about sustainability in the fashion industry;

- Aspects, such as lack of information, transparency in the industry, accessibility, variety of communication offered, lack of education and the price factor, are creating barriers for consumers to implement more sustainable practices in the fashion industry;

- Consumers want to be educated about sustainability by fashion companies.

\section{Conclusions}

As one was able to conclude throughout this research, sustainability in general is gaining more awareness between consumers. When speaking about sustainability implemented in the fashion industry, overall consumers identified its relevance and one can say that is affecting consumer choices in a positive way. However, not all are translating this concern into actual practices. The importance of a change in the industry and in the way of consuming was unanimously identified by consumers interviewed as essential.

Despite the growing interest on the topic, it was possible to observe that consumers are divided in two main groups. The ones that are already aware of sustainability in the fashion industry and consequently implement a variety of practices when making their buying choices. Meaning slowing down consumption, avoiding fast fashion, buying quality pieces that last a lifetime, being conscious about the production location and being the most informed possible about material composition and circularity concepts. This corresponds to the majority of the sample collected in the interviews. On the other hand, there are still consumers which, although recognizing the relevance of sustainability, are still not implementing it in their daily lives when speaking about fashion consumption. One was 
able to conclude that this is mainly due to a big lack of motivation, knowledge, information, education and accessibility as well as the higher prices. It was also possible to conclude, that the aspects lacking in consumers which are not implementing sustainability in their purchasing choices in the fashion industry, are the barriers and challenges identified by consumers that are already trying to implement it.

Furthermore, consumers in a general perspective revealed to be improving their behavior towards sustainability in the past years and are willing to continue improving it in the future. This revealed a strong tendency for a positive evolution. Consumers have the power and speak through their buying habits. That is why it is so important to change their mentality and consequently their way of acting. Observing the general paradigm of consumer behavior, it is crucial to focus on the ones that are not implementing sustainability in their buying choices yet. They are fundamental because they are the potential for further improvements to occur. The solution passes through educating consumers in a larger scale. This research enabled the realistic perception of consumer perspective in present times, which will enable companies to act accordingly in an informed way.

This research is contributing to the literature as it was possible to go a step ahead in the knowledge of the topic of sustainability in the fashion industry from a consumer perspective. At the same time, it was possible to create a better comprehension of practice and reinforce and confirm already developed concepts. For further research it would be relevant to deeply analyze consumers that are not implementing sustainability in their buying choices in the fashion industry with the concrete notion that having all consumers informed and aligned in the same line of thoughts, will enable better results. Sustainability implemented is a constant work in progress [26]. Informed and educated consumers are key for improvement. An informed person in conscience can only act for sustainability, whether in the fashion industry or elsewhere.

\section{Limitations}

In the development of this research, some limitations occur. Starting by the broadness of the concept of sustainability and sustainability in the fashion industry, it was a challenge to maintain the focus on the main objective without varying to other important and pertinent issues of this topic.

Additionally, a limitation that was identified was the size of the sample used for this research. Although the sample was the most heterogeneous possible having in mind a realistic consumer representation, the number of interviewees was still small.

Furthermore, in the chapter of data analysis one was confronted with a big limitation. The KH coder results were not that detailed as expected creating an additional difficulty for deeper analysis. Many interesting aspects shared in the interviews, were not directly translated in the graphs, tables and diagrams obtained. The results taken from $\mathrm{KH}$ coder did not enable the predicted accuracy in the data analysis, important words were missing due to the low frequency.

Finally, it is important to mention that another limitation is the fact that this research has focused only on Portuguese consumers, being an extrapolation of the data to a global analysis or conclusions not recommended.

Author Contributions: Conceptualization, R.C. (Rita Carvalho); methodology, R.C. (Rita Carvalho); validation, R.C. (Renato Costa) and L.P.; formal analysis, R.C. (Rita Carvalho); investigation, R.C. (Rita Carvalho); resources, R.C. (Renato Costa); data curation R.C. (Rita Carvalho); writing-original draft preparation, R.C. (Rita Carvalho); writing-review and editing, R.C. (Rita Carvalho) and L.P. supervision, N.A.; project administration, Á.D. All authors have read and agreed to the published version of the manuscript.

Funding: This research received no external funding.

Data Availability Statement: The data presented in this study are available on request from the corresponding author. The data are not publicly available.

Conflicts of Interest: The authors declare no conflict of interest. 


\section{Appendix A}

Table A1. Interview prototype.

\begin{tabular}{l} 
Research Objective \\
\hline Collect information to understand in which way sustainability in the \\
fashion industry is impacting consumer choices. \\
Share practices for companies and consumers in order to improve. \\
Integrate sustainability concerns as a main topic in consumer decisions. \\
\hline Collect information to understand in which way sustainability in the \\
fashion industry is impacting consumer choices. \\
Share practices for companies and consumers in order to improve. \\
Integrate sustainability concerns as a main topic in consumer decisions.
\end{tabular}

Data collection for companies to further understand consumer behavior in present times.

Data collection for companies to further understand consumer behavior in present times.

Offer companies and consumers a wider notion of current barriers in sustainability practices in the fashion industry. This will help to guide companies and consumers to possible solutions. Understanding the barriers may help in the improvement of solutions.

Prove that consumers have been changing their buying habits towards sustainability in the fashion industry.

Offer companies and consumers a wider notion of current barriers in sustainability practices in the fashion industry. This will help to guide companies and consumers to possible solutions. Understanding the barriers may help in the improvement of solutions.

Prove that consumers have been changing their buying habits towards sustainability in the fashion industry.

Create a variety of useful guiding ideas on how consumers can act sustainable in the fashion industry.

Collect information to understand in which way sustainability in the fashion industry is impacting consumer choices.

Share practices for companies and consumers in order to improve. Integrate sustainability concerns as a main topic in consumer decisions.

Prove that consumers have been changing their buying habits towards sustainability in the fashion industry.

Create a variety of useful guiding ideas on how consumers can act sustainable in the fashion industry.

Create a variety of useful guiding ideas on how consumers can act sustainable in the fashion industry.

\section{Question}

In which way does the concept of sustainability play an important role in your life?

(RQ1: Is sustainability relevant enough for consumers in their daily live in order to be the center of their decisions?)

Is sustainability in the fashion industry a relevant aspect for your daily purchasing choices? Why? Why not?

(RQ1: Is sustainability relevant enough for consumers in their daily live in order to be the center of their decisions?)

What is the context or motivation that led you to be concerned about sustainability in the fashion industry?

(RQ2: In which way is sustainability in the fashion industry integrated into consumer choices? What practices are consumers adopting?)

Nowadays, what kind of practices do you take towards the implementation of sustainability when buying fashion items? (RQ2: In which way is sustainability in the fashion industry integrated into consumer choices? What practices are consumers adopting?)

What are the challenges and difficulties you face when trying to buy sustainable fashion items?

(RQ4: What barriers do consumers face when speaking about sustainability in the fashion industry?)

In the last years did you improve your buying habits towards sustainable practices in the fashion industry? How?

(RQ3: Are consumers changing/improving their buying habits in the past years and do they want to continue changing it in the future? How? Why?)

What is the context or motivations that are lacking in order for you to implement sustainability in the fashion industry?

(RQ4: What barriers do consumers face when speaking about sustainability in the fashion industry?)

\section{What could make you act differently?}

(RQ3: Are consumers changing/improving their buying habits in the past years and do they want to continue changing it in the future? How? Why?)

How do you see sustainability in the fashion industry? What are the main associations you make when speaking about sustainability in the fashion industry?

(RQ: What are the main associations consumers make when speaking about sustainability in the fashion industry?

In which way do you think consumers play an important role in the implementation of sustainability in the fashion industry?

(RQ1: Is sustainability relevant enough for consumers in their daily live in order to be the center of their decisions?)

What are your long-term sustainability objectives? What do you want to improve?

(RQ3: Are consumers changing/improving their buying habits in the past years and do they want to continue changing it in the future? How? Why?)

As a consumer of fashion items (clothes, shoes and accessories), what sustainable changes would you like to see implemented by companies in the fashion industry?

(RQ: What are the main associations consumers make when speaking about sustainability in the fashion industry?)

If your voice was able to be heard by all the fashion companies and consumers in the world, what message and advice would you like to give?

(RQ: What are the main associations consumers make when speaking about sustainability in the fashion industry?) 


\section{References}

1. Garcia-Torres, S.; Rey-Garcia, M.; Albareda-Vivo, L. Effective disclosure in the fast-fashion industry: From sustainability reporting to action. Sustainability 2019, 9, 2256. [CrossRef]

2. Legere, A.; Kang, J. The role of self-concept in shaping sustainable consumption: A model of slow fashion. J. Clean. Prod. 2020, 258, 120699. [CrossRef]

3. Pal, R.; Gander, J. Modelling environmental value: An examination of sustainable business models within the fashion industry. J. Clean. Prod. 2018, 184, 251-263. [CrossRef]

4. Nayak, R.; Akbari, M.; Maleki Far, S. Recent sustainable trends in Vietnam's fashion supply chain. J. Clean. Prod. 2019, 225, 291-303. [CrossRef]

5. Mcneill, L.; Moore, R. Sustainable fashion consumption and the fast fashion conundrum: Fashionable consumers and attitudes to sustainability in clothing choice. Int. J. Consum. Stud. 2015, 39, 212-222. [CrossRef]

6. Todeschini, B.V.; Cortimiglia, M.N.; Callegaro-de-Menezes, D.; Ghezzi, A. Innovative and sustainable business models in the fashion industry: Entrepreneurial drivers, opportunities, and challenges. Bus. Horiz. 2017, 60, 759-770. [CrossRef]

7. Ciasullo, M.V.; Maione, G.; Torre, C.; Troisi, O. What about sustainability? An empirical analysis of consumers' purchasing behavior in fashion context. Sustainability 2017, 9, 1617. [CrossRef]

8. Brozović, D.; D'Auria, A.; Tregua, M. Value creation and sustainability: Lessons from leading sustainability firms. Sustainability 2020, 12, 4450. [CrossRef]

9. Biswas, A.A. Consumption value-gap analysis for sustainable consumption. Environ. Sci. Pollut. Res. 2017, 24, 7714-7725. [CrossRef]

10. Brown, B.J.; Hanson, M.E.; Liverman, D.M.; Merideth, R.W. Global sustainability: Toward definition. Environ. Manag. 1987, 11, 713-719. [CrossRef]

11. Geissdoerfer, M.; Savaget, P.; Bocken, N.M.P.; Hultink, E.J. The Circular Economy-A new sustainability paradigm? J. Clean. Prod. 2017, 143, 757-768. [CrossRef]

12. Purvis, B.; Mao, Y.; Robinson, D. Three pillars of sustainability: In search of conceptual origins. Sustain. Sci. 2019, 14, 681-695. [CrossRef]

13. Vogt, M.; Weber, C. Current challenges to the concept of sustainability. Glob. Sustain. 2019, 2, 6-11. [CrossRef]

14. Spangenberg, J.H. Hot Air or Comprehensive Progress? A Critical Assessment of the SDGs. Sustain. Dev. 2017, $25,311-321$. [CrossRef]

15. Ramos, T.B.; Caeiro, S.; Disterheft, A.; Mascarenhas, A.; Deutz, P.; Spangenberg, J.H.; Montaño, M.; Olayide, O.; Sohal, A. Rethinking sustainability: Questioning old perspectives and developing new ones. J. Clean. Prod. 2020, 258. [CrossRef]

16. Garcia, S.; Cintra, Y.; Torres, R.D.C.S.R.; Lima, F.G. Corporate sustainability management: A proposed multi-criteria model to support balanced decision-making. J. Clean. Prod. 2016, 136, 181-196. [CrossRef]

17. Stacchezzini, R.; Melloni, G.; Lai, A. Sustainability management and reporting: The role of integrated reporting for communicating corporate sustainability management. J. Clean. Prod. 2016, 136, 102-110. [CrossRef]

18. Maas, K.; Schaltegger, S.; Crutzen, N. Integrating corporate sustainability assessment, management accounting, control, and reporting. J. Clean. Prod. 2016, 136, 237-248. [CrossRef]

19. Lahsen, M. Toward a Sustainable Future Earth: Challenges for a Research Agenda. Sci. Technol. Hum. Values 2016, 41, 876-898. [CrossRef]

20. Lozano, R. A holistic perspective on corporate sustainability drivers. Corp. Soc. Responsib. Environ. Manag. 2015, $22,32-44$. [CrossRef]

21. Spangenberg, J.H.; Lorek, S. Sufficiency and consumer behaviour: From theory to policy. Energy Policy 2019, 129, 1070-1079. [CrossRef]

22. Ivanova, D.; Stadler, K.; Steen-Olsen, K.; Wood, R.; Vita, G.; Tukker, A.; Hertwich, E.G. Environmental Impact Assessment of Household Consumption. J. Ind. Ecol. 2016, 20, 526-536. [CrossRef]

23. Turnheim, B.; Berkhout, F.; Geels, F.; Hof, A.; McMeekin, A.; Nykvist, B.; van Vuuren, D. Evaluating sustainability transitions pathways: Bridging analytical approaches to address governance challenges. Glob. Environ. Chang. 2015, 35, 239-253. [CrossRef]

24. Prieto-Sandoval, V.; Jaca, C.; Ormazabal, M. Towards a consensus on the circular economy. J. Clean. Prod. 2018, 179, 605-615. [CrossRef]

25. Schaltegger, S.; Beckmann, M.; Hansen, E.G. Corporate Sustainability Meets Transdisciplinarity. Bus. Strategy Environ. 2013, 22, 217-218. [CrossRef]

26. Claxton, S.; Kent, A. The management of sustainable fashion design strategies: An analysis of the designer's role. J. Clean. Prod. 2020, 268, 122112. [CrossRef]

27. Turker, D.; Altuntas, C. Sustainable supply chain management in the fast fashion industry: An analysis of corporate reports. Eur Manag. J. 2014, 32, 837-849. [CrossRef]

28. Pedersen, E.R.G.; Earley, R.; Andersen, K.R. From singular to plural: Exploring organisational complexities and circular business model design. J. Fash. Mark. Manag. 2019, 23, 308-326. [CrossRef]

29. Armstrong, C.M.; Niinimäki, K.; Kujala, S.; Karell, E.; Lang, C. Sustainable product-service systems for clothing: Exploring consumer perceptions of consumption alternatives in Finland. J. Clean. Prod. 2015, 97, 30-39. [CrossRef] 
30. Egels-Zandén, N.; Hulthén, K.; Wulff, G. Trade-offs in supply chain transparency: The case of Nudie Jeans Co. J. Clean. Prod. 2015, 107, 95-104. [CrossRef]

31. Moretto, A.; Macchion, L.; Lion, A.; Caniato, F.; Danese, P.; Vinelli, A. Designing a roadmap towards a sustainable supply chain: A focus on the fashion industry. J. Clean. Prod. 2018, 193, 169-184. [CrossRef]

32. Jin, B.E.; Shin, D.C. Changing the game to compete: Innovations in the fashion retail industry from the disruptive business model. Bus. Horiz. 2020, 63, 301-311. [CrossRef]

33. Kirchherr, J.; Reike, D.; Hekkert, M. Conceptualizing the circular economy: An analysis of 114 definitions. Resour. Conserv. Recycl. 2017, 127, 221-232. [CrossRef]

34. Todeschini, B.V.; Cortimiglia, M.N.; de Medeiros, J.F. Collaboration practices in the fashion industry: Environmentally sustainable innovations in the value chain. Environ. Sci. Policy 2020, 106, 1-11. [CrossRef]

35. Sandvik, I.M.; Stubbs, W. Circular fashion supply chain through textile-to-textile recycling. J. Fash. Mark. Manag. 2019, 23 , 366-381. [CrossRef]

36. Brem, A.; Puente-Díaz, R. Are you acting sustainably in your daily practice? Introduction of the Four-S model of sustainability. J. Clean. Prod. 2020, 267, 122074. [CrossRef]

37. Saunders, B.; Sim, J.; Kingstone, T.; Baker, S.; Waterfield, J.; Bartlam, B.; Burroughs, H.; Jinks, C. Saturation in qualitative research: Exploring its conceptualization and operationalization. Qual. Quant. 2018, 52, 1893-1907. [CrossRef] [PubMed]

38. Yan, D.; Li, K.; Ye, J. Correlation analysis of short text based on network model. Phys. A Stat. Its Mech. Appl. 2019, 531, 121728. [CrossRef] 